\title{
EL «PRINCIPIO DE RESPONSABILIDAD» EN LA TEOLOGÍA DE ADOLPHE GESCHÉ
}

Fecha de recepción: 22 de noviembre de 2020

Fecha de aceptación: 05 de enero de 2021

RESUMEN: Adolphe Gesché indicó el «principio de responsabilidad» como uno de los que debían guiar el quehacer teológico. Ser responsable respecto de la fe y la razón, respecto de Dios y del hombre. En el presente estudio exponemos su comprensión y el desarrollo particular de esta tarea en su obra Dieu pour penser, atendiendo al doble movimiento teológico-fundamental —ad intra y ad extra-con el que solía articular sus escritos.

PALABRAS CLAVE: Teología Fundamental; Adolphe Gesché; principio de responsabilidad; fe; razón; Dios; Hombre.

\section{The "principle of responsibility" in Adolphe Geschés theology}

ABSTRACT: Adolphe Gesché indicated the "principle of responsibility» as one of those that should guide theological work. Be responsible for faith and reason, for God and man. In the present study we expose his understanding and the particular development of this task in his work Dieu pour penser, attending to the double theological-fundamental movement —ad intra and ad extra — with which he used to articulate his writings.

KEY WORDS: Fundamental Theology; Adolphe Gesché; principle of responsibility; faith; reason; God; Man.

Universidad Pontificia Comillas: sgmourelo@comillas.edu;

ORCID: https://orcid.org/0000-0002-2728-8556 
El presente artículo se sitúa en continuidad de otro publicado en Estudios Eclesiásticos sobre el carácter teológico-fundamental de la obra

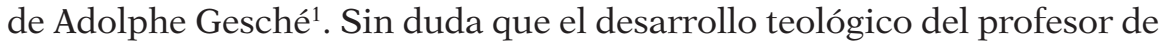
Lovaina todavía ha de ser objeto de estudio e inspiración pues, gracias a su pequeña «Summa Theologiae» ${ }^{2}$, Dieu pour penser, mostró un original ejercicio de la teología con oportunas intuiciones para su renovación ${ }^{3}$. Propuso a Dios, o por lo menos su palabra, para pensar algunas cuestiones en las que todos, creyentes y no creyentes, estamos concernidos al estar radicadas en lo más íntimo de nuestra enigmática identidad; una realidad, o su palabra, que provoca al pensamiento, independientemente de su conformidad o confesión, más allá del límite de lo pensable, conduciéndolo pedagógicamente hacia el exceso que representa.

En nuestro anterior estudio presentamos la obra de Gesché como un ejercicio de mostración teológica, en consonancia con las exigencias que la Teología Fundamental actual propone. Expusimos someramente sus principios epistemológicos, las funciones y tareas que daba al quehacer teológico, los dos momentos —ad intra y ad extra— propios de su ejercicio, para acabar ejemplificando estas cuestiones formales a partir de una de las líneas de fondo de su pensamiento: la «intersignificación» entre Dios y el hombre.

En este artículo profundizamos en uno de los principios epistemológicos que, según Gesché, debían orientar la práctica de la teología ${ }^{4}$. En concreto, en el «principio de responsabilidad». Dejando el segundo —el «principio de salutarité»- para otra eventual publicación, expondremos su desarrollo y aplicación, desde una doble perspectiva, típica de la Teo-

1 S. García Mourelo. "La monstratio theologica de Adolphe Gesché. Inspiración teológico-fundamental de su obra”. Estudios Eclesiásticos 92, n. . 360/1 (2017): 3-32.

2 Cf. L. Gil i Ribas. "La Summa Theologicae' de Adolphe Gesché”. RCatT 23 (1998): 225-230.

${ }_{3}$ Compuesta por: A. Gesché. Le mal. Dieu pour penser I. Paris: Cerf, 1993; Id. L'homme. Dieu pour penser II. Paris: Cerf, 1993; Id. Dieu. Dieu pour penser III. Paris: Cerf, 1994; Id. Le Cosmos. Dieu pour penser IV. Paris: Cerf, 1994; Id. La Destinée. Dieu pour penser V. Paris: Cerf, 1995; Id. Le Christ. Dieu pour penser VI. Paris: Cerf, 2001; Id. Le Sens. Dieu pour penser VII. Paris: Cerf, 2003. Se citarán por el título abreviado en francés, seguido de las páginas en esa edición y, después, de la edición en castellano, cuyas referencias están en la bibliografía final (p. e., cf. infra nota 5).

${ }^{4}$ Cf. A. Gesché. "Teología dogmática”. En Iniciación a la práctica de la teología, I. Introducción, editado por B. Lauret y F. Refoulé, 287-288. Madrid: Cristiandad, 1984 (1982). En adelante, “Teología dogmática”. 
logía Fundamental, delineada en el segundo capítulo de L’homme: «se ejerce [la función teológica] en una doble dirección: al servicio de la fe misma (ad intra) y al servicio de su presencia entre los otros discursos del hombre (ad extra)»5.

\section{LA SEMÁNTICA DE LA RESPONSABILIDAD}

Como Gesché anotó en una de sus fiches, «"Responder", "esponsal”, etc. tienen la misma raíz: spondere: comprometerse» ${ }^{6}$. Esa ha de ser una de las exigencias del teólogo, el primero de sus principios: «no ser "guardianes ciegos, perros mudos incapaces de ladrar, que sueñan, se acuestan y les gusta dormir" ${ }^{7}$. Su compromiso - y el compromiso de la misma teología- «con respecto a la fe, a la razón, a Dios y al hombre»", es motivo de interrogación, de diálogo y de respuesta; incluso de apología. Pues estos ámbitos, sin pretender exclusividad, sí le son específicos y, por eso, han de ser defendidos. Nada puede implicar mayores peligros que falsear a cualquiera de estos interlocutores. Por eso, tomarlos como interpelación e interrogarlos, es el mejor antídoto para mostrar su verdad o, al menos, aquella verdad que le corresponde decir a la teología y que sólo ella puede desvelar para no caer en el olvido. No solo el del logos de la fe, sino de aquello que sólo él profesa ${ }^{9}$.

Al hacerlo, en cierto modo, el logos de la teología toma distancia. Asume que no todo ha sido dicho y, también que, aquello que un día fue expresado, es necesario revisitarlo para ser mostrado con toda su fuerza y novedad. En esta aparente distancia entre la pregunta y la respuesta, entre el logos de la fe y aquellos elementos que le son propios, aunque no exclusivos, se pone de manifiesto la libertad y la autonomía del teólogo: «una libertad es siempre responsabilidad, respuesta (respondere, responder

\footnotetext{
5 L'homme, 46/47ss.

${ }^{6} N P$. LXII, 20 (6.6.91). be.uclouvain.fichiergesche.responsabilite_21. Las siglas NP hacen referencia al título que él mismo dio a sus cuadernos: "Ne pereant», evocando la traducción Vulgata de Jn 6,12: «ut autem impleti sunt dixit discipulis suis colligite quae superaverunt fragmenta ne pereant».

7 NP. LXXV, 95 (23.9.97) be.uclouvain.fichiergesche.theologie_1013. Donde remite a Isaías 56, 10.

8 "Teología dogmática", 287.

9 Cf. A. Gesché. La Teología. Salamanca: Sígueme, 2017, 13-27.
} 
de), y esa relación de alteridad (se responde a alguien, se es responsable ante alguien) es precisamente la que constituye una autonomía verdadera, dado que ella es responsable» ${ }^{10}$.

Si bien esta conexión, entre la responsabilidad y la respuesta, puede realizase con el auxilio de la etimología, en Gesché observamos que el trasfondo primero no es tanto lingüístico cuanto filosófico. Detrás del concepto de responsabilidad se muestra con patencia la influencia de E. Lévinas, en quien lo ético tiene estatuto de Filosofía Primera, pues pertenece y configura el ser y sus relaciones ${ }^{11}$.

Por este motivo, se puede afirmar que para Gesché el «criterio de responsabilidad» pertenece a la raíz misma de la teología. Pertenece a su ser y configura su reflexión, en la que trata de ofrecer libremente respuestas desde sí misma, desde su autonomía; respuestas de salvación a aquellas realidades que la interpelan (alteridad), que la cuestionan y cuestiona, pero con sumo respeto a ellas mismas - recordemos 1 Pe 3,1516- Respeto manifestado ante todo en la apertura de la pregunta; en el interrogante que el logos hace a las diversas realidades como respuesta a su interpelación y no en las respuestas cerradas que las clausuran, que no las respetan, que en-cierran la realidad:

«Existe, ciertamente, una distancia escatológica que se debe preservar, y también una distancia hermenéutica que deja un lugar abierto, sin cerrar. [...] "un locus inciertus, un respeto de enigma habita el corazón del locus certus, del lugar de la certeza" (Lucrecio). Los conceptos no son los únicos propietarios del conocimiento de Dios» ${ }^{12}$.

Después de haber indicado la hondura que para Gesché puede tener este principio, pasamos a mostrar cómo se concreta en su despliegue ante la fe, ante la razón, ante Dios y ante el hombre; con desarrollos diferenciados pero íntimamente vinculados: ad intra y ad extra.

\footnotetext{
${ }_{10}$ Le Sens, 69/80.

11 «Lo absolutamente Otro, es Otro (Autrui). Y la reconversión del Mismo por el Otro es un requerimiento de respuesta. El Yo no toma solamente conciencia de esta necesidad de responder, como si se tratara de una obligación o de un deber del que puede disponer; es en su posición misma, responsabilidad de parte a parte» (E. Lévinas. La realidad y su sombra. Libertad y mandato, Trascendencia y altura. Madrid: Trotta, 2001, 98).

12 Le Christ, 217/231.
} 
Dada la naturaleza de este estudio, al situarse en continuidad con el precedente, no ahondaremos en todas las cuestiones de manera similar, sino que remitiremos a otros desarrollos que complementan el aquí mostrado.

\section{RESPONSABILIDAD RESPECTO A LA FE}

«Responsable con respecto a la fe, como siempre lo ha sido (cogitatio fidei). Pero descubriendo mejor de lo que lo ha hecho la tentadora teología natural (valedera en su propósito, pero peligrosa en su omnipresencia) que su lugar propio está en esa constitución propia del hombre que podríamos llamar existencial de la fe, donde se sugiere y anuncia una verdad que no es accesible en ninguna otra parte» ${ }^{13}$.

Para la clarificación y profundización de este primer ámbito de responsabilidad hubiese sido iluminador el pretendido octavo volumen de Dieu pour penser. $\mathrm{La} \mathrm{Foi}^{14}$. Aun así, creemos que podemos esbozar desde lo publicado la «ortografía» (el conjunto de «normas» que la regulan) y la «gramática» (el arte de hablarla y escribirla correctamente) de este ámbito de pensamiento que es la fe. En función de estos contornos, podremos esbozar el modo como debe desarrollar su discurso propio en contraste con otros saberes, pues «lo que, efectivamente, se alcanza [...] es diferente en función precisamente del instrumento de conocimiento adoptado. Está condicionado, en una palabra, por el quodmodo» ${ }^{15}$.

Tal preocupación ha sido expresada por el teólogo de Lovaina en varias ocasiones en contraste, sobre todo, con la filosofía y la ciencia pues, comprender lo que motiva su modo propio equivale, no sólo a poner de manifiesto la seña de identidad, sino también su legitimidad y veracidad en todo lo que se muestre y se proponga. Hablando del acercamiento religioso a la realidad y sus posibilidades:

\footnotetext{
13 “Teología dogmática”, 287.

14 Cf. A. Gesché. Pensées pour penser I. Le mal et la lumiere. Paris: Cerf, 2003; Id. Pensées pour penser II. Les mots et les libres. Paris: Cerf, 2004. En el anverso de la contraportada de ambos. La editorial Sígueme ha publicado A. Gesché. La paradoja de la fe. Salamanca: Sígueme, 2013; aunque nosotros nos ceñimos al desarrollo diseminado del tema en Dieu pour penser.
}

15 Dieu, 30/31. 
"Yo prefiero utilizar aquí “desvelamiento” más que "revelación”, a causa del sentido demasiado autoritario y extrínseco que ha tomado a veces esta última palabra. Pero con ello aludo al mismo dato fundamental: la religión desvela, muestra, hace ver alguna cosa que está escondida detrás de aquellas que se saben [...]. Este es, en la investigación de la verdad de las cosas, el modo propio de la religión, que merecería ser estudiado más extensamente, en su diferencia respecto de la ciencia y de la filosofía ${ }^{16}$.

\subsection{AD INTRA}

Gesché comprende la fe como existencial de la persona ${ }^{17}$. Con semejante afirmación pretende ejercer una "función crítica» sobre aquellos desarrollos teológicos que se han dado en la historia, prescindiendo del dato de fe o tratando esa fe como simple dato añadido desde el exterior. En concreto, los excesos de la teología natural, que dejaba al margen la experiencia de fe para batirse, de igual a igual, con el racionalismo filosófico en su expresión atea, teísta o deísta. Esto bien podía ser una exigencia requerida desde el exterior, pero lo problemático era y es la exclusividad epistemológica, pues en el fondo suponía una renuncia a lo específico de su discurso y a la pretensión de verdad de su propuesta.

Con esta corrección, propone a la teología salir de cierto complejo frente a la filosofía y aportar, no sólo que el hombre-que-habla-de-Dios puede ser el-hombre-que-habla-a-Dios — señalando su indisoluble unidad ${ }^{18}$ sino también que, quizá, sea ese hombre —el hombre religioso-, el que en mejores condiciones esté para hacerlo, pues él es el «lugar natal» de este Dios que pensar, descubrir y conocer ${ }^{19}$. Por este motivo se hace necesario volver al lugar originario de la expresión de la fe «encontrándola de nuevo en su novedad, en su gratuidad, a partir de ella misma, como don que se propone a la acogida y no como una especie de experiencia que prolonga la experiencia del mundo ${ }^{20}$.

\footnotetext{
16 Le Sens, 24/34.

17 Cf. La Destinée, 126/128.

18 Cf. L'homme, 34/36. Sobre todo, la nota 3.

19 Cf. Dieu, 32/46.

20 La Destinée, 120/122.
} 
Partiendo de la visión antropológica de las «filosofías de la alteridad» ${ }^{21}$, Gesché fundamenta la fe en el carácter relacional del hombre. El hombre descubre y construye su identidad en la alteridad. No en o por lo otro, sino desde la distancia que le da lo otro permitiendo considerar (identificar) su sí mismo - diferancia, según Derrida ${ }^{22}$ - Este carácter «alterado», centrífugo; este descentramiento de la persona es llamado en términos cristianos fe, e indica «una profunda realidad y una misteriosa verdad de la existencia $»^{23}$. Aquella que nos descubre, no sólo nuestra identidad, sino la de aquello diferente de nosotros que nos hace descubrir quiénes somos mostrándose a sí mismo.

"El lenguaje es aquí de revelación"24, de visitación. La de una alteridad que da algo de sí manteniendo siempre su distancia y, a la vez, una irresistible atracción que lleva a la salida de sí. Acontecimiento y manifestación que pone de relieve el carácter autoimplicativo del lenguaje de la fe y su misma dinámica, al ser un momento segundo como respuesta a lo revelado. Por ese motivo, el lenguaje de la fe es esencialmente exodal, peregrino, en búsqueda de aquel que lo ha provocado y que le atrae. En cierta medida, trata de anticipar lo que todavía no tiene lugar —ou-tópico, podríamos decir-, es precedente a la Palabra definitiva y escatológica que todavía estar por decir».

Por este rasgo, la fe no sólo es consciente de la fragilidad de sus resultados, sino que lleva inscritos en ella misma los campos de inmanencia o de holgura de lo logrado, por lo que su carácter dinámico y novedoso es incontestable, no ya exigido desde fuera, sino en y desde ella misma. La fe es consciente del carácter sígnico, deíctico, de sus conceptos. Ellos son alcanzados y formulados por la fe en esperanza. Son categorías esperanzadas y esperanzadoras que apuntan más allá de sí mismas y por eso siempre están llamadas a dar que pensar. Si por el contrario, la fe pretendiera aferrarse a lo logrado con demasiada rapidez, se estaría negando a sí misma:

${ }^{21}$ Le Sens, 48ss./59ss.

22 Cf. Le Sens, 173 note 1/188, nota 46. La palabra «diferancia» y su formato, es un recurso gráfico de Gesché que, asumido de Derrida, refuerza el significado que quiere ofrecer.

${ }^{23}$ Le Sens, 64/76.

${ }^{24}$ L'homme, 36/38. 
«Por eso, ya santo Tomás, en una frase célebre, recordaba que el acto de fe (actus credendis) no termina (non terminatum) en el enunciado (ad enuntiabile), sino en el contenido al que se refiere, en la realidad en cuestión. La formulación dogmática (y a fortiriori la determinatio teológica) es un dicendum, un "eso que es posible decir", que remite más allá» ${ }^{25}$.

La fe no puede atrincherarse en sus seguridades, pues dejaría de tener gusto por la aventura y por el amor, convirtiéndose en ideología, en nomos reducido y reductor ${ }^{26}$. Hay pues que dar tiempo a sus propias palabras. Todo acto de fe y, quizá, sobre todo, lo que pueda ella decir, es acogida, camino, pregunta, vacilación, descubrimiento; lo que exige una «paciencia existencial» ${ }^{27}$, un saber demorarse a sí misma, permaneciendo en la cuestión y, en ella, a la par, ir creciendo: «Los conceptos tienen que permanecer vivos, inventivos, heurísticos, operativos. Cuando quedan fijos y, sobre todo, cuando parecen dictados por un simple interés especulativo, entonces se hunden ${ }^{28}$.

Desde aquí, casi como continuación obligada por el mismo discurso de la fe que-sale-de-sí, pasamos a considerar cómo opera la fe ad extra; cómo pone en juego los conceptos y categorías alcanzadas en diálogo con otras racionalidades y epistemologías; cómo muestra su capacidad de verdad y pone al descubierto la debilidad de otras propuestas.

\subsection{AD EXTRA}

Para realizar esta labor lo primero que señala Gesché en su descripción de la tarea justificativa de la teología, es un momento negativo. Sin duda, este es el más problemático, pues todos los esfuerzos fundamentadores, autocríticos y correctivos realizados ad intra, pueden resultar estériles si no se encuentra un espacio legítimo donde mostrarse. También, porque para desarrollar esta tarea se hace necesario el «respeto» arriba mencionado. Respeto como exigencia interna; mostrado y recibido con honestidad intelectual, donde se pone de manifiesto que, quizá, su discurso se muestre

25 Le Christ, 123/131.

26 Cf. La Destinée, 128/130.

27 Le Christ, 113, note 5/121, nota 159.

28 Ibid., 216/229. 
«loco» para otros, "pero una locura que no puede ser alienación o perversión y que hay que mostrar que no atenta contra el hombre, sino, al contrario, lo conduce a su trascendencia ${ }^{29}$.

Este momento negativo tiene una estrecha relación con la concepción y el uso de la razón que propone la misma fe. En términos clásicos, en cómo la fides qua exige un determinado despliegue de la racionalidad para llegar a formular la fides quae, aspecto que desarrollaremos en el próximo apartado. Por este motivo, nos detenemos en la consideración de la plausibilidad de la palabra de la fe junto a otros discursos.

¿Por qué la fe puede gozar de un espacio propio y específico desde el que pueda dialogar con otras epistemologías? ¿Qué visos hay en el conocimiento humano que puedan legitimar, e incluso reclamar, su presencia y su propuesta?

Las epistemologías que son objeto de especial diálogo para Gesché son aquellas que reducen la compresión de lo real a su propio monopolio. Aquellas que, no tanto por su estatuto, cuanto por su uso excluyente, omiten otras voces, otras comprensiones que, en el fondo, lo que hacen es poner de manifiesto su propia fragilidad y limitación. «Lo que aquí está en juego es todo el tema de la legitimidad de los distintos lenguajes a propósito de una misma realidad ${ }^{30}$.

Son, pues, unos preámbulos epistemológicos los que trata de reclamar y salvaguardar. Por este motivo podríamos decir que la fe no realiza su tarea negativa frente a la filosofía o la ciencia, cuanto frente a un determinado uso de la epistemología científica o filosófica:

«El error fundamental, que es el de todos los imperialismos científicos, consiste en aplicar, creyendo hacerlo en nombre del logos universal con el que se le confunde indebidamente, la jurisdicción de un logos particular, propio de un ámbito (filosofía, por ejemplo) a otro ámbito (el de la fe, por ejemplo)» ${ }^{31}$.

Señal de ello es que no duda en acoger, integrar y pensar desde lo que viene de esos ámbitos cuando hacen justicia a la totalidad de comprensiones, en su caso, al hombre religioso, a la realidad de la fe cristiana o a una visión abierta y dinámica del cosmos. En este sentido son abundantes las

\footnotetext{
29 L'homme, 50/51.

30 Dieu, 44/43.

31 L'homme, 51/53.
} 
simpatías y referencias a J. L. Chrétien, J. Ladrière, P. Ricoeur, E. Lévinas, I. Prigogine, G. Steiner, H. Arendt, J. Kristeva, P. Claudel y otros tantos, que dejan una puerta abierta, un ámbito de respiro y de diálogo a otras disciplinas, e invitan a una reflexión más amplia.

«[...] estamos (quizás) en el umbral de una nueva y tercera modernidad. La que sigue a la muerte de Dios y a la muerte del hombre. En la era que se anuncia y en la que quizás ya hemos entrado, se vuelve a pedir tímidamente a Dios (ese retorno a lo sagrado, como se dice, pero yo prefiero llamar recurso - correr de nuevo- a lo sagrado o, mejor aún, un recurso a lo Santo). En una palabra el mundo se pone de nuevo a escuchar a la fe ${ }^{32}$.

En concreto, para mostrar la función y la naturaleza de la fe, acudirá a algunos aspectos de la teoría literaria de Ricoeur. La función de la fe en el conocimiento es similar a la función de la refiguración, la intriga y la ficción en la narrativa. La refiguración señala este momento segundo de lo dado - aspecto que hemos puesto de manifiesto al hablar de la dimensión declarativa de la fe-. La intriga revela el carácter extático, ou-tópico, deíctico, ya comentado, de la fe. La ficción es quizá la más problemática por su carácter peyorativo. En su etimología, «ficción» se refiere al acto de dar forma y a la cosa formada, indicando una manera de realizar aquello que se desea expresar. Desde aquí, la ficción en la narrativa articula y da forma a la realidad al relatarla.

Entendida de esta manera y aplicado al género «evangelio», en búsqueda de una racionalidad que medie entre historia y fe, lo que se nos trasmite en ellos es la elaboración de los evangelistas. Su fe se convierte en ese hilo conductor de todo el relato, en esa forma por la que ellos «nos confían a Jesús en el marco de una figura a la que nos invitan a adherirnos, y que a ellos tanto les conmovió, como si se tratara de una revelación» ${ }^{33}$. La función literaria de la ficción es la función de la fe en la elaboración teológica ${ }^{34}$. Podríamos hablar de una fe narrativa que elabora sobre lo acaecido un relato y, en él, proyecta su destino. De esta manera, la fe pone de relieve su propiedad fundamental de ir más allá de lo constatable, que posibilita ver —en el sentido joánico del término—en lo constatable; no

\footnotetext{
32 Le mal, 167/169; Le Cosmos, 90-91/221.

33 Le Christ, 98/104.

${ }^{34}$ Cf. A. Espezel. "L’identité narrative de Jésus". Revue Catholique Internationale Communio, 30, $\mathrm{n}^{\circ} 1$ (2005): 89-97.
} 
detrás ni después, sino en. La fe da la capacidad de captar lo entredicho en el texto, mostrando una presencia ausente que acompaña el relato y lo capacita para mostrarse de modo diferente. No es que se deje de lado lo dicho en el texto, sino que desvela lo entredicho. Hay, pues, un espacio, un silencio que reclama, por su apertura, una mirada identificadora. No es un espacio vacío, sino entregado. Se facilita ese espacio para nuestra confesión, «aquella que se convierte en un don que nosotros hacemos para el Señor» ${ }^{35}$.

De esta manera Gesché trata de presentar como plausible la capacidad gnoseológica de la fe y muestra cómo estas insinuaciones del pensamiento contemporáneo pueden expresar el intellectus quaerens fidem, un verdadero intellige ut credas, en el que la razón —logos-, lejos de una renuncia a sus caminos, se detiene, quizá exhausta por su interminable búsqueda, pidiendo consuelo, aliento y luz a quien un día dejó de escuchar. La fe, desde su vulnerabilidad, desde la incertidumbre de lo logrado y lo por lograr, desde la seguridad que ofrece al dar respuestas en esperanza, se torna, ahora, en manantial, en descanso de un logos solitario, infantilmente emancipado, que dejó de tener en cuenta lo excesivo, lo creativo y lo inventivo, que aportaba el simple hecho de la búsqueda y del interrogante.

«La fe sigue siendo, lo mismo que el arte o la felicidad o la acción, una manera de abrir al hombre, y de abrirlo con todas las de la Ley, a algunos aspectos de la realidad que se muestran esquivos a otras consideraciones. La fe, en el orden que le pertenece, tiene su propio lugar en el concierto de los comportamientos y de los discursos humanos. Al menos da que pensar (Kant, Ricoeur). Más aún, con frecuencia se revela como la mejor salvaguardia del eco de una verdad profunda, pero que a veces se esconde, se olvida o parece inaccesible» ${ }^{36}$.

\subsection{El Lenguaje de La Fe como paLabra ÚNICA}

Junto a esta tarea negativa, que cae por su propio peso en el interior de todos los discursos, la fe, su logos, tiene una función positiva o transpositiva, en la que se ejerce una hermenéutica o mediación en la información y justificación de su sentido.

\footnotetext{
35 Ibid., 111.

36 La Destinée, 127/129.
} 
En el ámbito formal, epistemológico, ya hemos señalado lo que aporta la fe: ese carácter extático, utópico, esperanzador que no sólo lanza al pensamiento y a la acción, sino que provoca una tarea autocrítica, un continuo cuestionamiento de las propias disposiciones y métodos sobre los objetos propios. Ahora bien, estas funciones extáticas y autocorrectoras no son específicas de la fe, aunque la constituyan. En definitiva, es la propia constitución y existencia del hombre, como símbolo originario, la que posibilita una continua indicación hacia la realidad a la que tiende buscando nuevas formas de representación. Por eso, múltiples expresiones humanas como la literatura, el arte, lo ético, pueden aportar esto mismo: «La fe es una de las moradas en la casa del logos humano. Este no está hecho solamente de razón científica o filosófica. El arte (Gadamer), la acción (Blondel), el bien, el amor también tienen su racionalidad y su capacidad de decir la verdad $»^{37}$.

Por este motivo, quizá sea en el ámbito material, de contenido, donde la fe puede aportar su palabra, donde puede explicitar su novedad, pues su tensión remite, no a un simple más allá de lo que se dice, que ya es mucho, sino a una alteridad radical y concreta: Dios mismo - ex-auditu - que llama a la obediencia $\multimap o b$-audire - y a la conversión ${ }^{38}$. Recordemos a Gregorio de Nisa inspirado en Flp 3,13, donde la epéktasis de la fe remite hacia su unión con Dios: es decir, hacia el polo objetivo de la fe ${ }^{39}$.

Este originario carácter sígnico lo desarrollaremos en el punto que versa sobre el hombre y trataremos de clarificar los perfiles del polo objetivo en el apartado sobre Dios. Lo que aquí podemos indicar es que su logos, ya marcadamente teo-lógico, quizá esté mejor situado que el de otros ámbitos de conocimiento para mostrar al hombre un ámbito concreto (salvación) o una alteridad «definida» (Dios) hacia quien dirigirse. Más allá del saber (ciencia) o del sentido (filosofía), se sitúa la cuestión lacerante e inexcusable del destino (teología), que abarca a la verdad y al sentido en su ultimidad. Pues «su pasión consiste en hablar de aquello que hace que el destino sea un camino del hombre. "Homo desideriorum es”, tú eres, oh Daniel, un ser de deseos (Dn 9,23; 10,11.19)» ${ }^{40}$.

37 Ibid., $126 / 128$.

38 Cf. Le Sens, 108/122.

39 Cf. Gregorio de Nisa. Sobre la vida de Moisés, II, 233 (BPa 23. Madrid: Ciudad Nueva, 1994, 205).

40 Le Sens, 85/98. 
Ya introducidos en la especificidad del logos de la fe, consideramos a continuación cómo opera la razón, el logos de la fe, dentro de estos límites y con estas condiciones que se impone a sí misma. Ella es la que da el paso de una fe como existencial de la persona, a la articulación teológica concreta.

\section{RESPONSABILIDAD RESPECTO A LA RAZÓN}

«Responsable con respecto a la razón, como lo ha sido siempre (fides quaerens intellectum). Pero estando más atenta que nunca a todo lo que este mundo exige actualmente de apertura de espíritu a los análisis críticos de la "pura razón" (Kant) con vistas a una "razón más amplia" (Weil) que no puede eludir» ${ }^{41}$.

En este camino de responsabilidad, que hemos comenzado a recorrer desde la fe, Gesché invita a ejercerla respecto a la razón. Su uso condicionará el resultado de la propuesta creyente. Por este motivo se debe caer en la cuenta de lo que condiciona a la misma razón — su contexto y su herencia- que, en el caso de nuestro autor, creemos que se sitúan como en dos círculos concéntricos superpuestos. Su contexto es el de la cultura europea contemporánea y el de la pasión del hombre de fe que busca hacer inteligible, para sí mismo y para los demás, el mensaje que ha recibido; mensaje que hereda con unas categorías propias de su tradición que son reelaboradas o profundizadas desde las herramientas conceptuales que le aporta el contexto actual. Se da, por tanto, una circularidad simultánea entre lo heredado, de fuera y de dentro, y lo exigido, de fuera y de dentro. Por ello no puede haber una exclusión de la fe del logos universal, ni una renuncia del logos en el acto de fe, pues supondría un "suicidio intelectual del hombre ${ }^{42}$ y, como consecuencia, la caída en el fideísmo y la superstición. Por este motivo, el cristiano «tiene derecho a pensar para creer (Intellige ut credas) ${ }^{43}$.

En la misma línea se situó Clemente de Alejandría, autor al que Gesché recurre en varias ocasiones para este tema. Frente al peligro de la gnosis, había que hacer una gnosis verdadera. Un mayor esfuerzo de inteligibilidad:

\footnotetext{
41 “Teología dogmática”, 287-288.

42 L'homme, 50/52.

43 Dieu, 48/46.
} 
«Desde la fe [se va] a la gnosis» ${ }^{44}$. «Es necesario, pues, elevarse desde esa misma fe y crecer en ella por la gracia de Dios, para adquirir en la medida de lo posible la gnosis entorno a Él $»^{45}$, o como cita nuestro autor: «Cuando empecemos a reflexionar debemos introducir a nuestros oyentes la fe, porque ella es también un testimonio digno de credibilidad (Protéptico, $\mathrm{X}, 95,3) »^{46}$. Y es que, en definitiva, «es un hermoso riesgo pasar al campo de Dios» (Protéptico, X, 93)» ${ }^{47}$.

Ahora bien ¿cómo lograrlo? ¿Cómo fundamentar hoy día, desde sí misma, desde la fe, la racionalidad? ¿Cómo reconocer que el logos tiene un lugar que es la fe? ¿Cómo puede, desde este locus, mostrar su capacidad de verdad? ¿Quién y cómo le puede ayudar en esta tarea?

Para tratar de responder a estas preguntas nos preguntaremos primero, desde el interior de la fe, sobre los fundamentos de su propio logos, sobre la familiaridad y estrecha connaturalidad entre fe y razón, para encontrar, en un segundo momento, las influencias, los apoyos, las críticas y las propuestas, ofrecidas o recibidas, ad extra.

\subsection{AD INTRA}

En el ámbito de la fe, como en cualquier otro, la razón puede caer en el riesgo de la explicación —erklären-, de pretender controlar ese incontrolable e inmedible que trata de ser la respuesta o existencial de la fe. Por ese motivo, quizá, nuestro autor da pistas para situar la misma racionalidad en el interior de la fe y, así, circunscribirla en un modo concreto de ejercicio, ensanchando y elevando la razón (medida) a logos (creatividad) para llegar a comprender -Verstehen-.

En continuidad con la «paciencia existencial» propia de la fe, comentada más arriba, Gesché hace un primer llamamiento a la contemplación, con el fin de evitar un uso precipitado de la razón. Afirma que «hablar demasiado rápidamente [...] es dejar escapar el acontecimiento» ${ }^{48}$, en el 311)

44 Clemente de Alejandría. Stromata. V, I, 2.4 (FP 15. Madrid: Ciudad Nueva, 2003,

45 Ibid. VII, X, 55.3 (FP 17. Madrid: Ciudad Nueva, 2005, 441).

46 Le Sens, $161 / 176$.

47 La Destinée, $128 / 130$.

48 Le Cosmos, 52/187. 
que en su contemplación ya se da una comprensión profunda de la verdad que lleva al asombro y a la alabanza.

Esta distinción y prevención metodológica nos lleva a tomar conciencia de un conocimiento previo por participación, o consonancia entre lo conocido y el «órgano» de conocimiento, y de unas estructuras racionales comunes en la realidad. Para la fundamentación teológica de tal racionalidad, Gesché formula la hipótesis de un principio lógico que se extiende en todo lo creado «desde el deseo creador inicial» ${ }^{49}$. Sitúa, fiel a su hipótesis, la racionalidad de la fe en un lugar específico: pensar las cosas desde Dios, fundamentado en el mismo Logos divino por el cual son pensadas (creadas) todas las cosas.

Desde la triple concepción del logos estoico (spermatikos, endiathetos y prophorikos), afirmará «una simiente, una disposición y un anuncio de racionalidad, de sentido y de palabra ${ }^{50}$ que anima la creación entera dotándola de un mandato de invención, lejos ya de una predeterminación fisicista. Bajo esta formulación, cercana a los Padres apologistas - como Justino- y a los teólogos del Logos — sobre todo Clemente de Alejandría y Orígenes-, y al margen de las desviaciones doctrinales de esta comprensión de la revelación y del ser mismo de Dios ${ }^{51}$, nuestro autor quiere indicar la estrecha relación lógica entre Dios (Logos tou Theou), la creación (oikos tou Theou Logou) y el hombre (demiurgos logicos). Fundado en Dios como Sujeto-Logos, considera la tierra de manera «razonable» y «racional» (logike) y al hombre como el-viviente-a-imagen-del-Logos (zoon logikon). Desde esta conexión habrá para el creyente un mandato intrínseco a la fe: «volver a dar sentido, finalidades, razón (logos), razones para creer ${ }^{52}$ desde su propio logos teo-lógico y ejercer, así, una demiurgia diaconal que consiste «en guardar un mundo que tiene una estructura de eternidad $»^{53}$. Ahora bien, ¿cómo preservar esta reserva teo-lógica? ¿Cómo articular esta racionalidad? ¿Cómo formularla?

49 Ibid., 63/197.

50 Ibid., $19 / 160$.

51 Para mantener el equilibrio dirá: «Cierto, lo hemos dicho suficientemente, este Logos divino no es inmanente al mundo (como un alma), sino trascendente (como una persona o un sujeto). Pero trascendencia quiere decir, sin embargo, presencia (lo que es bastante más que inmanencia)». (Ibid., 107/235).

52 Ibid., 101/230.

53 Ibid., 237. 
Como hemos indicado, este logos no busca explicaciones, sino más bien una comprensión más profunda de la realidad desde una razón más amplia. Su labor no consistirá tanto en hacer encajar la realidad en unos esquemas previos, cuanto en descubrir la lógica inscrita en ella misma desde el estrecho vínculo entre el Creador, la creación y la criatura. Esta familiaridad, invisible e inaprehensible fuera del ámbito de la fe, sólo es posible narrarla, representarla, «inventarla $»^{54}$.

En este aspecto creativo, inventivo —aunque no sólo—, Gesché es deudor del pensamiento de Pascal, que tantas veces releía. Por eso participa de sus limitaciones y de sus posibilidades. Desde él se comprenden las reservas constatadas hacia el pensamiento científico-positivo, llamado por Pascal «geométrico» ${ }^{55} \mathrm{y}$, también, hacia el filosófico ${ }^{56}$. Pascal criticará el reducido concepto de razón limitado a estas dos epistemologías; parece que ésta sólo puede manejarse desde ellas. Por eso abrirá el concepto de razón intentando salir de sus estrecheces mediante una nueva epistemología, la del corazón — raisons du coeur-, lugar, también, de la fe.

Pascal no renuncia a la razón, eso sería caer en la superstición, pero sí al modo como se aprehenden ciertas realidades. Por ello, aun afirmando que «el pensamiento constituye la grandeza del hombre ${ }^{57}$, pues «está visiblemente hecho para pensar» ${ }^{58}$, querrá ir más allá de un determinado uso de la razón, situándola en otro lugar —el corazón—, con una epistemología diferente —el espíritu de finura-, que evoca la contemplación requerida por Gesché con un origen y fundamento trascendente ${ }^{59}$ : «La fe es diferente de la prueba: la una es humana, la otra es don de Dios. "Justus ex fide vivit": de esta fe que Dios mismo deposita en su corazón,

${ }^{54}$ Cf. Ibid., 188. La semántica se vincula más a la invención como creación, fundada en el Logos creativo de Dios, que a la fantasía arbitraria del hombre.

55 B. Pascal. Pensamientos. ed. Brunschwick. Madrid: Alianza, 2004, 17ss. En adelante Pensamientos.

56 «Señor — dijo Pascal al Sr. de Saci- os pido disculpas si opino así ante vos sobre la teología en lugar de permanecer en la filosofía, que era mi único objeto; pero he llegado ahí insensiblemente. Es difícil no entrar en estas cuestiones, cual sea la verdad que se trate, porque es el centro de todas las verdades» (A. Villar-B. Pascal. Conversación con el Sr. de Saci. Salamanca: Sígueme, 2006, 51).

57 Pensamientos, 346.

58 Ibid., 146.

59 «La fuerza patética simbólica consiste en ver de una sola ojeada la totalidad de un proceso, mientras que la racionalidad descompone demasiado los elementos» (Le mal, 156/160). Cf. Pensamientos, 72. 
cuyo instrumento es muchas veces la prueba "fides ex auditu"; pero esta fe está en el corazón y hace decir, no "scio", sino "credo" ${ }^{60}$.

Para recorrer este camino, a la búsqueda de una racionalidad que muestre que la religión no es contraria a la razón, Pascal apuntará el método específico para pensar como es debido: «el orden del pensamiento está por comenzar por sí mismo, por su autor y por su fin» ${ }^{61}$. Después de constatar por varios caminos la imposibilidad de la filosofía y de la ciencia para su pretensión, verá que «el último paso de la razón es reconocer que hay una infinidad de cosas que la superan ${ }^{62}$. Lo que llevará a Pascal a abandonar el terreno teórico y a pasar al práctico con su argumento de la apuesta - semejanza con Gesché sobre la que volveremos en el apartado sobre el hombre-. Con todo, podemos encontrar una vía teórica que, entre críticas y alabanzas, da una solución conceptual a la aparente ausencia de racionalidad: el imaginario.

El hombre se mueve entre dos infinitos: su origen y su destino. Entre ellos se puede vislumbrar la amplitud del cosmos y la proporción del hombre. Cuando la vista se detenga en la consideración de tal contingencia, Pascal exhortará a "que la imaginación vaya más allá» ${ }^{63}$, pues cuando llegue a su límite, cuando la imaginación se pierda en el pensamiento, será «la más grande nota sensible de la omnipotencia divina ${ }^{64}$. Esta vía racional es la que Gesché utilizará para mostrar y narrar el logos de la fe: «Para descubrir o construir el sentido, el hombre no puede confiar únicamente en la racionalidad, sino que necesita otro campo más amplio, el del imaginario ${ }^{65}$.

60 Pensamientos, 248.

61 Ibid., 54.

62 Ibid., 267. Balthasar, comentado a Pascal, dirá: «De acuerdo con lo dicho, resulta evidente que la experiencia cada vez más profunda del Dios eternamente incomprensible conduce al creyente a una gnosis cristiana peculiar que deviene en pistis, cada vez más central, entregada cada vez más total a la supremacía cada vez mayor del Dios libre» (H. U. von Balthasar. Gloria. Una estética teológica. I. La percepción de la forma. Madrid: Encuentro, 1985, 155).

${ }_{63}$ Pensamientos, 72.

${ }^{64}$ Ibid., 72.

65 Le Sens, 143/157. Nótese aquí cómo hereda el prejuicio «reductivo» de la racionalidad de Pascal. Más adelante, en la misma página, podemos leer: «[...] este imaginario, como "potencia unificadora", va infinitamente más allá de nuestra razón. Ciertamente, nosotros no podemos dejar a un lado la razón — no hay nada peor que el delirio, la pérdida del sentido de la realidad y la emergencia de fantasmas-, pero la razón tiene sus límites, "los límites de la razón pura": ella no puede explicar todo el ardor, toda la efervescencia, todo el tumulto que hace de nosotros unos seres vivos». 
Con esta epistemología, más constatable en el mundo literario, Gesché tratará de encauzar aquellos símbolos y promesas de las que habla el kerigma de la fe, por ejemplo en la liturgia, cuando «ella nos invita, con un simbolismo conmovedor, a que nosotros mismos penetremos en los misterios que todo este imaginario despliega» ${ }^{66}$, o en la teología, «a través de las representaciones a las cuales ella recurre, como a metáforas siempre vivas ${ }^{67}$.

Para nuestro autor, la racionalidad literaria tiene la potencialidad de profundizar y articular el discurso teológico. Ésta no sólo posee un carácter verificador y crítico en la elaboración del discurso teológico, también tiene una capacidad especulativa de carácter ontológico sin igual ${ }^{68}$ :

«Hay una metafísica de las palabras [...] Las palabras tienen un significado y una historia, una densidad propia, en parte independiente de su uso y de la cosa (res) que quieren expresar. Y que, de alguna manera, a veces se dictan a este fin y, en ese sentido, la preceden, sino la causan. Vox sonat rem (Cicéron, Definibus, 11, 2, 6)» ${ }^{69}$.

\subsection{AD EXTRA}

Después de haber indicado las inquietudes, problemas y posibles vías de solución en la fundamentación y articulación del logos inscrito en la fe, podemos rastrear las mismas pretensiones en el momento en el que el logos de la fe dialoga con otros logoi, sobre todo, con la filosofía. De ella es deudora, lo hemos constatado con su influencia pascaliana, y sobre ella ejercerá una función crítica, para poner de manifiesto aquello que pervierte la compresión de lo real o para potenciar aquello que le hace justicia y, de esta manera, proponer su argumentum Dei.

66 Ibid., $157 / 172$.

67 Ibid., 158/173.

68 Así lo constata J. C. Barcellos comentando a Gesché: «Como se vê, a contribução original de Gesché à problemática que vimos estudiando está no situar a literatura não apenas enquanto fonte de subsídios para elaboração de uma teologia, mas, sobretudo, como um lugar de veificação da pertinência e relevância de qualquer discurso teológico que se pretende produzir». (J. C. Barcellos. O drama da salvação. Espaço Autobiográfico e Experiência Cristã em Julien Green. Juiz de Fora: Ediçoes Subiaco, 2008, 126).

${ }^{69}$ A. Gesché. Les mots et les Livres, 10. 
Al modo como Fontaine recoge el encuentro entre Pascal y el Sr. de Saci en su Entrevista, donde se perciben los límites y posibilidades de Montaigne y Epicteto y, en definitiva, de la filosofía para la praxis y la reflexión del creyente, podemos rastrear en Dieu pour penser un proceso similar con el desarrollo filosófico. Ciertamente no podemos recorrer todas las aportaciones positivas o negativas - no es tampoco el método de Gesché-, pero sí podemos detenernos en algunos ámbitos de especial diálogo — crítico o de integración-que emergen en los diferentes desarrollos elaborados por nuestro autor.

En primer lugar, desde una vertiente de crítica y superación, nuestro autor está especialmente preocupado por las objeciones al cristianismo hechas desde el llamado "círculo de la sospecha», o ateísmo metafísico, científico o cosmológico (Feuerbach, Nietzsche) y su vertiente existencial (Sartre y Merleau-Ponty), pues son las que actualmente funcionan como tópicos en posturas arreligiosas. En sus diversos desarrollos sale al paso de las críticas con el argumento central que se ha utilizado para inocular estas filosofías: lo que realmente era objeto de rechazo no era tanto Dios, cuanto a una determinada idea de Dios, que poco tenía que ver con la concepción cristiana, pues negaba la autonomía humana, verdadera reivindicación de estos desarrollos ${ }^{70}$.

Sin duda se caía en el error cuando se pensaba - por ejemplo Feuerbach o Nietzsche-, que el hombre, al afirmar a Dios, negaba sus propias posibilidades para prestárselas al Absoluto pues, en el fondo, lo buscado y pretendido no era tanto una negación de Dios cuanto el rechazo de una determinada idea de Dios que atentaba contra el hombre. En la misma dirección Sartre decía que Dios (su idea o confesión) impedía que el ser humano fuera él mismo, pues si había una esencia que precedía y gobernaba la existencia, el hombre ya no era sujeto de su historia, sino que estaba gobernado por otro ${ }^{71}$. De fondo se estaba gestando una infantil emancipación del ser humano que consistía en mostrar su incompatibilidad con Dios, llegando a decir que el hombre — la conciencia moral- moría en contacto con el Absoluto (Merleau-Ponty) ${ }^{72}$. Estos desarrollos, pretendiendo salir de la alienación, eliminaron la alteridad, implicando la

\footnotetext{
${ }^{70}$ Cf. L'homme, 119/116; Le Sens, 51-52/62.

71 Cf. Le Sens, 52/62; La Destinée, 42/44; L’homme, 75-76/75.

72 Cf. L'homme, 119/117; Le Sens, 164/179.
} 
ausencia de referencias, un encerramiento donde el hombre pasaba a ser «su propio sol» ${ }^{73}$. Para que el hombre viviese, lejos de la alienación y pudiera reconstituir su esencia y autonomía, tenía que morir Dios.

Había dos errores en el origen de su crítica. El primero, antropológico, al olvidar que la libertad se constituye en - y gracias a - la mediación de la alteridad. Ignorando tal referencia no se hace más que pretender eliminar el enigma que somos, lo que con el tiempo ha resultado una empresa imposible, pues «el hombre es un ser que siempre ha ido a llamar a la puerta de los dioses para comprenderse ${ }^{74}$, no con la intención de buscar un «tapa-agujeros» que eliminara todos sus interrogantes, sino con la inquietud de buscar la alteridad radical que mejor le revelara su identidad y resolviera su enigma lejos de toda tautología y autorreferencialidad. "Como la muerte de Dios ha dejado al hombre solo, a este no le queda más remedio que volverse contra sí ¿pero es sostenible esta situación?» ${ }^{75}$ Veremos más adelante que no. Junto a esta falacia antropológica, también había un error teológico - que tan sólo apuntamos, pues nos detendremos en él en el apartado sobre Dios-. Consistía en hablar de Dios a partir de unas ideas previas, en lugar de dejarle a él decirse en el lugar donde ha querido revelarse.

Con todo, Gesché trata de integrar en su método una de las intenciones de esta sospecha fundada en Descartes. El primer aspecto es el papel de la interrogación. Como ya hemos señalado más arriba, la duda, el interrogante se sitúa en sus inicios epistemológicos. Gesché la considera necesaria, aunque siempre en su justa medida: «Ya hemos conocido la era de la sospecha y conviene no olvidar sus lecciones. [...] En una palabra, la sospecha tiene su sitio. Pero no se puede abusar de él» ${ }^{76}$.

Otro de los cuestionamientos de la sospecha que nuestro autor integrará en su desarrollo será la prevención contra toda representación de Dios que lo mida según nuestras necesidades e intereses y, como consecuencia, lo falseen, haciendo lo mismo, de paso, con el hombre. Tema al que dedicará un capítulo en el volumen sobre Dieu, bajo el título: «La idolatría siempre posible» ${ }^{77}$.

${ }_{73}$ Le mal, 162/165.

${ }^{74}$ La Destinée, 46/48.

75 Le mal, 40/43.

76 La Destinée, 17/18-19.

77 Dieu, 153-162/139-147. 
En esta justa medida - criticando lo negativo, valorando y asumiendo lo positivo-, podemos seguir el diálogo y la recepción equilibrada de otras corrientes actuales que tratan de superar los errores de las anteriores. Porque,

«[...] quizá, tras la era de la sospecha (Freud, Marx, Nietzsche), debería venir lo que yo llamaría la era "de la sospecha de la sospecha" (cuyos testigos podrían ser Ricoeur, Lévinas, Kristeva), para que se rasgue el velo y podamos descubrir la bendición de la alteridad para salvarnos del encerramiento ${ }^{78}$.

Esta labor de diálogo fecundo, de potenciación del pensamiento realizada con maestría, es señal de la búsqueda de inteligibilidad de las palabras propias de la fe. Ese es el único camino para «reconciliar a la fe consigo misma, una fe que quiere seguir siendo accesible a un discurso que cuente con la razón, pero que al mismo tiempo desea seguir siendo libre y sin constricciones ${ }^{79}$.

Con todo, no vamos a detenernos en la recepción positiva que hace de cada pensador, pues para mostrarla de modo admirable están sus propios escritos. Lo que sí vamos a señalar son las distancias que toma especialmente con respecto a E. Lévinas. Nos detenemos en este autor por su patente influencia, positiva y negativamente, en los contenidos e intuiciones de fondo, y porque en la recepción de su propuesta es donde, quizá, mejor se revele la función transpositiva de la teología; lo que propone desde su propio logos.

Para profundizar sobre este aspecto podemos acudir a desarrollos que muestran cómo su propio logos no se ajusta a este desarrollo filosófico concreto, aunque en buena parte le sea deudor. El factor común sitúa en el papel del amor y el exceso, y en el valor objetivo que éstos traen consigo. Tanto en las relaciones entre los hombres, como en la relación de Dios con el hombre, Gesché dará un paso más desde el exceso de la caridad.

En las relaciones entre los hombres, nuestro autor va más allá de lo ético como puro desbordamiento de un deseo de transcendencia, pues la relación ética, en el fondo, busca o encuentra la manifestación del

\footnotetext{
78 Le Sens, 59/70.

79 La Destinée, $18 / 20$.
} 
Otro a través del rostro del otro ${ }^{80}$; tanto por la constitución de la propia identidad gracias al espacio creado por la alteridad del «heme aquí» que impele sin violencia a la responsabilidad ${ }^{81}$, como por la salida para conciliar al sujeto con la muerte, aunque ésta pueda llegar a ser un acto metafísico. "Morir por lo invisible: he aquí la metafísica» ${ }^{82}$.

Respecto del primer motivo, Lévinas huye de una violencia o imposición en el respeto y en la responsabilidad ante la víctima - en el caso del mal- pero, como señala Gesché, «su manera de hablar de esta responsabilidad la hace tan pesada como si fuera culpabilidad ${ }^{83}$, ejerciendo así una presión que paraliza la libertad, fundamento de la responsabilidad ante la víctima. Lo crucial en este aspecto, no es tanto la responsabilidad, cuanto la libertad en la que se funda, verdadera aportación del cristianismo ${ }^{84}$. Por otra parte, en el ámbito ético son evidentes las reticencias de Lévinas a la palabra «amor», aunque él mismo quisiera integrarlo en su discurso ${ }^{85}$. Gesché ve en el amor el verdadero exceso capaz de recrear las situaciones irracionales generadas por el mal:

«No basta con ir más allá de los hechos económicos o culturales a través del puro desbordamiento ético, pues la ética no es un exceso [...] una ética sin una pasión que está conducida por un deseo mayor y que le excede (deseo filosófico, metafísico o teológico) es una práctica que puede apagarse sobre sí misma, consumirse y morir lentamente» ${ }^{86}$.

Esta cuestión está fundada, no en la subjetividad ni en la alteridad del otro que manifiesta veladamente el rostro del Otro, sino en la praxis

\footnotetext{
${ }^{80}$ No como trascendencia en la inmanencia, sino como inmanencia en la presencia elusiva de la trascendencia. El otro está en la huella de Dios: «Ser a la imagen de Dios, no significa ser el ícono de Dios, sino encontrarse en su huella» (E. Lévinas. Humanismo del otro hombre. México: Siglo XXI, 1974, 82).

81 Cf. E. Lévinas. De otro modo que ser, o más allá de la esencia. Salamanca: Sígueme, 1999, 183.

82 E. Lévinas. Totalidad e infinito. Ensayo sobre la exterioridad. Salamanca: Sígueme, 1987, 59.

83 Le mal, 94/97.

${ }^{84}$ Dieu, 92-94/85-87, 127-131/116-120.

85 Lévinas huye de este encuentro como «amor», pues lo ve con ambigüedad y como un modo de violencia, imposición y control muto, «egoísmo de dos». Cf. E. Lévinas. Totalidad e infinito. 265-282. Cf. Le mal, 94-95/96-97.

${ }^{86}$ Le Sens, 100/114.
} 
de Jesús (Mt 20,34), «camino escogido por Dios en el combate contra el mal» ${ }^{87}$.

En lo que se refiere a la revelación de la identidad del hombre, Gesché señalará que no es suficiente una alteridad —con relación a los otros o al cosmos-, sino que «el hombre se conoce también por aquello que le trasciende y le arranca desde lo alto ${ }^{88}$. Una altura no como expresión del Infinito, sino con un rostro concreto, el del Dios-Amor. Este conocimiento está fundado en la revelación de Dios, en un decir de Dios en el que se dice a sí mismo. Es una «revelación del amor, de la revelación que es amor ${ }^{89}$. Por ella, el hombre se reconoce en su enigma pues, al igual que en el amor, al mismo tiempo que uno es llevado y escondido en el otro, uno puede ser revelado y descubierto. «Este es, sin duda, todo el secreto o el milagro del amor ${ }^{90}$.

Esta cuestión es quizá la que marca mayor distancia entre los dos pensadores. Pues si bien es cierto que en la relación hombre-Dios, Lévinas constata en el ser humano una tensión hacia el Infinito, en el sentido inverso de la relación - Dios-hombre-, apenas encontramos desarrollos ${ }^{91}$ : "A este propósito, es sabido que Lévinas, tan cerca de nosotros, no puede hacerse a la idea de un Dios hecho hombre ${ }^{92}$. Todo lo contrario que en Gesché, donde llevado por la pasión, sitúa en Dios un deseo por darse a conocer que está presente intratrinitariamente -Verbum incarnandum ${ }^{93}$ y en su economía - desde el deseo de un mundo como espacio necesario para la relación con el hombre ${ }^{94}$, a la necesidad de comprenderse en y por nosotros ${ }^{95}$ - . Pero de estas cuestiones, no exentas de complicaciones y reflejadas ahora con inexactitud, nos ocuparemos en el apartado sobre Dios. Aquí basta retener este paso hacia adelante que Gesché da desde el logos de la fe.

87 Le mal, 95/98.

88 Le Sens, 165/180.

89 Ibid., 163/178.

90 Ibid. 163/178.

91 Cf. E. Lévinas. “¿Un Dios hombre?”. En Entre nosotros: ensayos para pensar en otro. Id. 69-78. Valencia: Pre-Textos, 1993.

${ }_{92}$ Dieu, 112/102.

93 Cf. Le Christ, 229/244.

94 Cf. Le Cosmos, 96/226.

${ }^{95}$ Cf. Le Sens, 181/197. 


\subsection{Posibilidades de lo EXCESivo EN LA RAZÓN}

Si una palabra puede designar a la razón, con la «precisión» requerida en el ámbito de la fe, es la palabra exceso. Exceso de lo recibido; exceso en el modo de desarrollo; exceso en lo ofrecido.

Exceso respecto de lo recibido. Pues la racionalidad en el lugar de la fe nace y se desenvuelve con y desde un dato abierto que la desborda y no le pertenece ${ }^{96}$ : la revelación. Por ello, junto al asentimiento por el testimonio divino acogido en la fe, la razón, en su limitación, es empujada continuamente a la comprensión y expresión del Misterio, siempre inconcluso e inabarcable. «Si comprehendis, non est Deus» (Agustín), «eres algo mayor que lo que puede ser pensado» (Anselmo) son hitos que nos recuerdan que, si bien el hombre es capax Dei, no es capax definiendi Deum. Dios se sustrae en todo concepto, pero no al concepto. Mostrando que, aun siendo capaces de significarle por la analogía, Él la supera porque la precede y fundamenta, abriendo, así, unos ámbitos de holgura en la reflexión que le nombra y posibilitando una ruptura de los cercos inmanentes de la propia razón. Por eso, la teología guarda siempre una reserva etiológica y escatológica, un principio corrector sobre su origen y sobre el destino apuntado. Desde ahí, recordemos cómo los grandes escolásticos definieron el articulus fidei como «articulus fidei est perceptivo divinae veritatis temdem in ipsam».

Fundada en la certeza propia de la fe, en esta razón hay también un exceso respecto del modo de desarrollo. Ella ausculta semillas de pensamiento hacia su convergencia y denuncia aquellas que falsean ciegamente la propia razón. Rehabilita conceptos elaborados en el pasado desde la amplitud de la experiencia que los provocó, accesible todavía por la naturaleza responsiva de la fe. Para ello trata de ensanchar la racionalidad con el recurso a lo excesivo, al imaginario. Lo que lleva a considerar de nuevo aquello que tiempo atrás se pensó con las categorías del logos humano - la filosofía, la literatura, la ciencia-, pero aportando la expansión provocada por la epéktasis que la constituye. Como señala Gesché: «resulta indispensable para el hombre la existencia de proposiciones excesivas (o parcialmente excesivas), para que aprenda, como aquí decimos, que la vida no adquiere su sentido si se encuentra clausurada al don ${ }^{97}$. Estas proposiciones excesivas, salvaguardas desde el logos de la

\footnotetext{
96 Ibid., 137, extraído de Pensamientos, 267.

${ }_{97}$ Le Sens, 13/23.
} 
fe en la Escritura, la Liturgia, la Tradición, la Teología, etc., desvelan el exceso de lo ofrecido a otras racionalidades. No sólo por la especificidad propia respecto de ámbitos comunes de compresión (el hombre, el cosmos, el sentido, la muerte...) sino, también, por la Buena Noticia que porta y es su mensaje. En ella hay ruptura, novedad y exigencia.

Ruptura y novedad en la imagen de un Dios en la que, más allá del carácter incompleto o inacabado del hombre y de la imagen de Dios distante y alienante del teísmo, se muestra capax homini en la «molestia que se ha tomado» para su visitación ${ }^{98}$; en la oferta a participar de su propia vida como cumplimiento de su alianza; en lo ya dado y recibido por el hombre como criatura; en el intercambio del «llena de gracia» (Lc 1,28) y el «hágase en mí» (Lc 1,38) de María ${ }^{99}$.

Y exigencia porque «dependerá de nuestra actitud el conocimiento y la imagen de Dios que los hombres se hagan ${ }^{100}$. Actitud que explicitará la fe y a quién la provoca en las obras de caridad, de inteligencia y de justicia que realice. Obras como expresión del leguaje autoimplicativo de la fe, del actio fidei, señalando así su irremplazable e irrenunciable dimensión práxica; obras que llevarán a término la responsabilidad de la fe y de la razón en el «practicar a Dios» ${ }^{101}$.

Constatada la circularidad entre el crede ut intellige y el intellige ut credas, nuestro autor propone la expansión del lenguaje de la fe en el age ut intelligas et credas, que pone de manifiesto el conocimiento práctico de Dios, como expresión de la fe o de su búsqueda. Una teología expresada, $a b$-probada y explorada en una teo-praxia y, desde ella, potenciada y ampliada.

\section{RESPONSABILIDAD RESPECTO A DIOS}

«Responsabilidad con respecto a Dios, como fue evidentemente su tarea desde su nacimiento (teo-logia). Pero observando con mayor atención, que, en cierto sentido, es depositaria del misterio de Dios, el cual la ha confiado la misión de mostrar con claridad que él es salvación y buena noticia ${ }^{102}$.

98 Cf. L'homme, 120/117.

99 Ibid., 122/119.

100 La Destinée, 174/175.

101 Ibid., 175/176.

102 “Teología dogmática”, 288. 
Una de las mayores preocupaciones de Gesché, omnipresente en los temas abordados, son las imágenes sobre Dios. En función del modo de conocimiento adoptado y de cómo comprenda aquello a lo que se ha llegado, el hombre se falseará a sí mismo o podrá dirigiese a un Dios que «merezca»su confesión.

Si bien el modo de conocimiento ya ha sido tratado en los apartados sobre la fe y la razón, en este momento se impone la reflexión sobre el «medio» que adopta el teólogo de Lovaina para conocer en su hipótesis de trabajo. Reflexión en la que, a su vez, entran en juego la fe y la razón que hemos descrito. Dieu pour penser, supone que se tiene una determinada concepción de Dios que «sirve» para poder reflexionar, por eso resultará fundamental que se clarifiquen los perfiles del polo objetivo de la fe, de aquello que la ha provocado, sostiene e impulsa. «Lo más importante es pensar correctamente (orthos) a propósito de los dioses (Platón, Leyes, X 888 a-b)» ${ }^{103}$.

Sobre este aspecto, que supone discreción, intervalo, paciencia, amplitud, versarán los diferentes capítulos del volumen tercero de su colección. La síntesis de esta pretensión de fondo la encontramos en el último: «Sobre la idolatría siempre posible» ${ }^{104}$. En él, después considerar la idolatría del «dios ético»y «filosófico», se detiene en la mayor perversión: el falso «dios teológico». Éste es el que más nos interesa, pues toca directamente la racionalidad del teólogo, - aunque, bien es cierto, que los otros pueden estar latentes y ejercer su influencia. El «dios teológico» es el punto de Arquímedes para levantar compresiones, para pensar el mal, al hombre, el cosmos, etc. Si fuese erróneo, ¿qué mundo de falsas especulaciones se levantaría? La perversión estaría motivada por una inversión, pues al tratar con el verdadero Dios — no como el de la «ética» y la "filosofía»— y falsearlo, se le estaría acomodando a nuestros intereses y a nuestras necesidades inmediatas. Quien es verdaderamente Absoluto respecto de nosotros quedaría relativizado, por lo que perdería su alteridad, su distancia para ser creador y para ser instancia crítica de lo creado por Él. Si esto sucediese la fe dejaría de tener las cualidades que hemos desarrollado más arriba —ou-tópica, ex-tática, etc.- para convertirse en mera tautología y para caer en las críticas que desde Feuerbach la han considerado como potencia de compensación de las limitaciones humanas. Por este motivo radical, siempre amenazante en todo discurso

103 Dieu, 10/12; Le Christ, 9/9.

104 Dieu, 153-162/139-147. 
sobre Dios, en la tarea de la teología siempre deberá estar de fondo la preocupación y la lucha contra toda forma de idolatría y politeísmo, en busca de la identidad del Dios verdadero.

Para encontrar tal identidad —en el fondo cualquier identidad (la de Dios, la de Jesucristo, la de los otros, la nuestra)_, Gesché seguirá la estela de la hermenéutica fenomenológica de Ricoeur y así hablará de una identidad narrativa ${ }^{105}$. Habrá que acudir a aquellos lugares donde se ha hablado de Dios, donde su identidad ha transitado, donde Él se ha dicho. No tanto en aquellos motivados por la especulación, cuanto en aquellos en los que la revelación ha motivado tal decir. En estos lugares es donde la identidad de Dios se ha ido configurando. Son los lugares de su nacimiento para nosotros. «Hablar de una búsqueda de Dios en su lugar natal significa que uno propone como camino el de la hermenéutica religiosa. [...] Aquí: la búsqueda de Dios allí donde se habla de él y, a partir de ahí, poner al día aquello de que se trata ${ }^{106}$. Así, antes, o como primer paso de la reflexión teológica, habría una «teografía» —se permite nuestro teólogo inventar esa palabra-, unas coordenadas previas para proporcionar materia y lugar de reflexión.

En esta «teografía» se constatarán dos loci privilegiados: el primero y ad intra: Jesucristo, Palabra encarnada, Logos accesible en cuanto fundador de nuestro logos. El segundo, ad extra: el cosmos, lugar de la gratuidad, del don, de la oferta de un lugar para el hombre donde ejercer su libertad y su invención.

\subsection{AD INTRA}

Gesché partirá de la máxima pascaliana, o de su significado, «no conocemos a Dios sino por Jesucristo» ${ }^{107}$ para comenzar su itinerario hacia una pertinente imagen Dios y corregir los perfiles erróneos que se han adoptado o añadir otros nuevos. De esta manera, además de reajustar el excesivo cristocentrismo en la teología y en la fe cristiana, querrá mostrar lo que Dios ha dicho sobre sí mismo. En concreto, en su capacidad de ser en lo otro, de ser hombre hasta las últimas consecuencias.

\footnotetext{
105 Cf. Le Christ, 78ss./83ss.

106 Dieu, 14/15.

107 Cf. La Destinée, 171/172-173; Le Christ, 12/12, 34/37.
} 
Éste será un punto central y reiterado en todo su discurso sobre Dios. Con él querrá aportar una instancia crítica frente a rasgos de teísmo filosófico, como la inmutabilidad y la impasibilidad, que no han sido suficientemente correlacionados con la imagen bíblica de Dios y se muestran como afirmaciones a mantener por fidelidad a la Tradición y al Magisterio, sin ofrecer una síntesis satisfactoria ${ }^{108}$. Si bien ambos aspectos son tratados normalmente en estrecha relación, el que es objeto de especial profundización es el segundo. La pasibilidad será considerada como una especial investigación de nuestro autor, cuyo origen se encuentra ya en su tesis doctoral, como ya mostramos en nuestro anterior estudio ${ }^{109}$. Por este motivo, dada las limitaciones de este artículo, pasamos a delinear el movimiento ad extra de la responsabilidad respecto de Dios.

\subsection{AD EXTRA}

Con la misma intención y método, aprender de Dios lo que él es, Gesché ofrecerá una serie de aspectos para renovar el discurso sobre Dios ad extra. Su pretensión no será la exhaustividad, cuanto la evocación. Para ello tratará de mostrar la plausibilidad de una relación que potencie el protagonismo del hombre y así poner de manifiesto los rasgos diferenciadores del Dios en quien creemos ${ }^{110}$. En concreto, utiliza un término sorpresivo, no carente de dificultad: el juego. Es un concepto situado fuera del ámbito religioso que bien puede servirnos para condensar los diferentes rasgos del Dios cristiano ofrecidos por nuestro teólogo. Detrás de ellos se esconden categorías como creación, don, gracia... y, en su

108 Cf. S. del Cura. "El sufrimiento de Dios en el trasfondo de la pregunta por el mal. Planteamientos teológicos actuales". RET 2/3 (1991): 353; L. F. Ladaria. El Dios vivo y verdadero. El misterio de la Trinidad. Salamanca: Secretariado Trinitario, 1998, 392. En cambio, el primer aspecto, la inmutabilidad, ha sido integrado sobre todo a partir del artículo de K. Rahner. "Para la teología de la encarnación". En Escritos de Teología IV. 4. ${ }^{\text {a }}$ ed., 131-148. Madrid: Cristiandad, 2002. En especial a partir de la p. 139 y la nota 3 .

${ }^{109}$ La llega a considerar "mi investigación sobre un "Dios patético"» (Le Christ, 37/40). Cf. A. Gesché. La christologie du 'Commentaire sur les Psaumes' découvert à Toura. Gembloux: Duculot, 1962, que sigue de cerca A. Grillmeier. Cristo en la tradición cristiana. Salamanca: Sígueme, 1997, 578-585. La referencia donde hemos tratado esta cuestión, S. García Mourelo. "La monstratio theologica de Adolphe Gesché". 20-27.

110 Cf. Dieu, 84/77. 
familia semántica, gratuidad, alteridad, autonomía, decisión, propuesta, trascendencia, exceso. Foráneamente, la semántica del juego evoca una acción intencionada, pero gratuita y abierta. El destino de un juego no está predeterminado, sino sujeto a su mismo desarrollo. En él se destacan dimensiones como la participación, la creatividad, la invención. Tiene una motivación lúdica, de disfrute, gozo y diversión. ¿Tiene algo que ver todo esto con Dios? Para nuestro autor, sí.

«Jugar! pero ¿qué resonancia tiene en nosotros esta palabra? ¿se podría decir que Dios mismo juega con la creación? Pues teológicamente es esta idea - o esta idea arriesgada - la que ahora despunta y no puede ser eludida. ¿Idea blasfema e injustificable o permitida y gozosa?»111.

Todo lo que sugiere esta palabra puede integrar el intento de recuperación de una categoría "tan nuestra» como "creación», cuestión que se propone en el cuarto volumen de su colección. En dicho proceso de rehabilitación, aparte del fecundo diálogo con la filosofía y con la ciencia, nos desvelará otro trazo a recuperar de los perfiles de Dios. Al esbozar el espacio que Dios ha creado para nuestra relación nos estará diciendo algo sobre sí mismo y sobre nosotros.

La idea de juego relacionada con la creación no es extraña a la tradición cristiana, como puso de manifiesto H. Rahner en El hombre lúdico ${ }^{112}$. Lejos de indicar la idea de azar (tyche) o arbitrariedad, Gesché quiere significar con ella la gratuidad del acto creador. La creación no responde a una necesidad interna de Dios, sino a un acto (techne) libre y gratuito de condescendencia con el que Dios disfruta: «en sus obras Yahvé se regocije» (Sal 104,31). Podríamos decir que el cosmos, como el juego, por sí mismo carece de razón, de necesidad que lo reclame - Dios no lo necesita en absoluto-, en cambio participa de la razón, del Logos que lo ha creado. En función de él, el cosmos posee un principio fundamental de creatividad, un mandato de invención que se despliega sostenido por las estructuras lógicas que lo fundaron. Responde a un proyecto intencionado en estrecha relación con su origen, pero distinto de él. «Cuando Dios descansó el séptimo día, pidió al mundo continuar su invención. Sin embargo, Dios no está ausente. "El silencio que sigue a la música de Mozart, es también de Mozart" ${ }^{113}$.

\footnotetext{
111 Le Cosmos, 130/256.

112 Cf. Ibid., 144/269.

113 Ibid., 77/209.
} 
De esta manera, al crear un espacio inventivo, distinto de sí y del hombre, Dios indica el modo de relación que quiere establecer con su criatura y la confesión relativa que podemos hacer de él ${ }^{114}$. Es una relación de sujeto a sujeto, aunque no simétrica, pues está lejos de la inmanencia y del panteísmo. En el cosmos, podríamos decir que Dios se arriesga al ejercicio de libertad del hombre en un lugar distinto de sí, a-teo dirá Lévinas como buen judío, aunque creado para la relación. Siendo esta una afirmación arriesgada, con ella no se quiere expresar un espacio de ausencia radical entre Dios y el hombre - los temas del Tsimtsum judío o la Contractio patrística-, como si Dios se materializase y se modelara espacialmente en función de lo creado. Gesché, con este espacio de separación y distancia, indica que el mundo no se comprende como amenazado y poseído por Dios, sino que es diferente de Él, aun teniendo su consistencia en Él y en el acto soberano que lo ha presidido.

Este principio de diferenciación también revela la responsabilidad del hombre: «hay establecido en la creación un espacio que significa el derecho y la vocación de inventar y crear» ${ }^{115}$. Ad imago Dei, el hombre podría ser considerado como causa segunda. Instalado señorialmente como señor del cosmos, tiene el encargo de continuar la tarea de invención a imagen y semejanza de su Creador. Para Gesché la imagen del jardín del Génesis evoca, no sólo la contemplación de la belleza de la creación sino, también, las ideas de trabajo, laboriosidad, cuidado, invención. Dios no nos coloca ociosos en el mundo, sino con el mandamiento de crecer y multiplicar, abundando en la concepción de un mundo inacabado:

«Dios, si se puede hablar así, no simplemente ha creado la tierra. Ha creado esta morada que es suya, lo hemos visto, y nos la ha dado. Así ella es oikos antrhopou y así nosotros, convertidos en intendentes (demiurgos), hacemos de ella nuestra oikumene. Tierra que es por eso mismo tierra de comunión, donde Dios, en esta morada común, nos entrega su vida y su presencia» ${ }^{116}$.

114 «Hablar de monoteísmo relativo, es decir que en el monoteísmo cristiano hay, no diría yo que una falta, sino una abertura donde cabe el hombre y que condiciona la confesión y quizá incluso la concepción del Dios que es efectivamente único Dios». (A. Gesché. La paradoja del cristianismo. Salamanca: Sígueme, 2011, 55).

115 L'homme, 87/86.

116 Le Cosmos, 89/220. 


\subsection{DEUS EX-UBERANS}

Las reflexiones condensadas sobre Dios muestran el fundamento de su método teológico. Pensar las cosas desde Dios y llevarlas al exceso, sólo es posible en la medida en que las categorías que tenemos sobre Él nos capacitan para tal empresa. No es de extrañar que, para lograrlas, el teólogo de Lovaina nos sitúe y haga transitar lejos del dios de la abrupta teología natural, que marcaba límites al Dios de la revelación cristiana; del dios que ahogaba la libertad y la autonomía del hombre; del deus ex machina que gobernaba el universo con indiferencia ante lo que en él sucediese.

Contemplar la kénosis divina manteniendo los límites que ella misma nos impone y, a partir de ella, atisbar lo que la ha podido motivar, es el intento de Gesché. La gratuidad del juego inventivo como llamada al ejercicio de una libertad creadora y responsable, es expresión de una nueva epistemología teológica que responde positivamente tanto a la naturaleza humana como al Dios cristiano: la epistemología del exceso $^{117}$. Exceso como consecuencia del uso de la razón en el terreno de la fe. Exceso como expresión del Dios exuberante que lo ha motivado.

Cierto es que las imágenes sugeridas sobre Dios no se pueden llevar, paradójicamente, hasta el exceso, pero ellas nos sitúan en los márgenes de la inmanencia divina para estar más cerca y a la vez más distantes del Deus ex lex, del Dios al que no hemos de dictarle prohibiciones en nombre de nuestras concepciones previas ${ }^{118}$. Más lejos no podemos ni debemos ir. Quizá, tampoco sea necesario, pues son suficientes para considerar la pertinencia y plausibilidad de su evocación.

Un Dios que se desvela como salida-de-sí, cuya naturaleza, si se nos permite hablar así, es reciprocidad mutua, aunque asimétrica, provocación, relación permanente y desbordante de amor, es el único que puede ayudarnos a pensar en los límites de nosotros mismos y de lo pensado. Es quien es capaz de elevar el pensamiento por encima de los límites autoimpuestos y hacernos descubrir la correspondencia lógica entre el Logos creador y el logos de la fe para, desde ahí, ajustar el conocimiento de la realidad a su propia razón. Esta concepción de Dios

\footnotetext{
117 Cf. Le Sens, 94ss./108ss.
}

118 Cf. Dieu, 73/69. 
desvela, no una inmaterialidad divina que se despliega aleatoriamente, cuanto la afirmación cristiana de la correspondencia gratuita entre Dios y el hombre. Ellos «se significan recíprocamente, se inter-significan». Podríamos decir que «Dios es la semántica del hombre (y el hombre la semántica de Dios); que pueden interpretarse el uno en el otro» ${ }^{119}$. Por eso puede nuestro autor, siguiendo a Pascal, afirmar la centralidad de Jesucristo, Verbo encarnado, como signo supremo de ese vínculo. Donde Dios se expresa tal cual es y realiza plenamente su designio en su propia humanidad y donde el hombre puede mirarse, comprenderse y confiarse como realización absoluta de aquello a lo que está llamado ${ }^{120}$.

Constatando las continuas remitencias hacia el ser humano en la búsqueda de la identidad de Dios, no es de extrañar una convicción de fondo de Gesché: «La cuestión del hombre no es menos teológica que la cuestión de Dios» ${ }^{121}$. Hablar de Dios, o de cómo es Dios, lleva directamente al ser humano y hablar del hombre en toda su integridad conduce a pensar correctamente acerca de Dios. Ante esto, ante el Dios cristiano, ¿dónde queda la hipótesis de Merlau-Ponty en la que el hombre moría en el contacto con el Absoluto? Lejos de una diástasis amenazadora e insalvable, la naturaleza divina mostrada - naturaleza de kénosis - desvela la verdad de nuestra naturaleza. El capax homini de Dios, sólo es compresible desde el capax Dei del hombre - aunque ontológica y teológicamente sea prioritaria-y, en sentido inverso, el capax Dei del hombre se verifica como posibilidad real en el capax homini de Dios. Es en Jesucristo donde ambas naturalezas coinciden, inciden juntas, se dan sin separación y se hacen realidad sin confusión en la misma persona.

Desde este prisma, maravilloso por sus colores y contrastes, somos llevados, casi por la lógica misma del discurso, a hablar del hombre. Ahora no sólo desde la fe o desde el uso de la razón en este ámbito, también desde la imagen de Dios que el creyente puede esbozar como válida y verídica para hablar de sí mismo.

119 Le Christ, 51/56.

120 Cf. Le Sens, 168/184; La Destinée, 171/172.

121 L'homme, 10/12. 


\section{RESPONSABILIDAD RESPECTO AL HOMBRE}

«Por último, con respecto al hombre, como hizo constantemente en su ambición por responder al deseo mismo de Dios (fil-antropía). Pero con una conciencia más viva de que el mundo de hoy, víctima de numerosas amenazas de muerte, necesita más que nunca que viva Dios para que viva el hombre. La teología no se puede permitir el lujo de un discurso ilusorio, debe servir. Debe situarse en el concierto de los discursos del hombre, sin timidez pero sin arrogancia, porque en el núcleo mismo de su anuncio sobre Dios posee una clave de humanismo. Incluso en el momento en que despuntan ciertas antropologías de la muerte del hombre, tendrá la misión de responder al desafío antihumanista en nombre de esa visión teo-icónica del hombre que hallamos en las primeras páginas de la Escritura ${ }^{122}$.

La pretensión de fondo en el discurso antropológico de Gesché, consiste en arrancar al ser humano de su propia inmanencia, no como preámbulo a la acogida de la propuesta que Dios le hace, sino como su misma expresión. La transcendencia y el término concreto de ésta es el rasgo distintivo que la teología puede aportar a la diversidad de discursos sobre el hombre. Desde la lógica ou-tópica de la fe y desde la imagen de un Dios ex-ubernate, propone una antropología deliberadamente teologal que, «al introducir la dimensión de la trascendencia, lejos de hacer morir al hombre a su contacto, lo sitúa dentro del piélago sin orillas de una aventura infinita ${ }^{123}$.

Un complejo tapiz de material precioso será el que nuestro autor trate de reconstruir y renovar siguiendo la lógica de la fe. Para ello, qué mejor camino que el de tratar de contemplar al hombre desde Dios, desde una altura por encima de nuestras miras que dé cuenta de nuestra hondura. " "Cada uno tiene la altura" que corresponde a su profundidad, aquella a la que Dios ha descendido»"24. Así, la teología, lejos de abandonar su objeto específico - Dios mismo-, aporta su palabra única sobre el ser humano mostrando lo que Dios ha dicho sobre el hombre. En la medida en que la teología sepa transmitir, desde su propio logos, la propuesta de

122 “Teología dogmática”, 288.

123 L'homme, 93/91.

124 Ibid., 115/112. 
Dios al hombre, podrá ser antropología. Pero ¿qué es lo que Dios propone al hombre? ¿Qué somos a sus ojos?

\subsection{AD INTRA}

El teólogo de Lovaina desarrollará su antropología teologal desde los clásicos e irrenunciables temas de la creación y la filiación. Ambos serán releídos, profundizados y actualizados. Desde ellos o con ellos como término, establecerá conexiones con antropologías actuales pretendiendo mostrar desde el interior del logos de la fe, lo que éste dice sobre el hombre.

En particular son tres aspectos específicos los aportados: que en todo hombre hay un inviolable, que nada es inexorable y que la realidad no es sólo lo que es, sino lo que podría ser. Estas tres aportaciones, expuestas sintéticamente en el volumen sobre el hombre, serán recurrentes y tratadas en el resto de la colección de manera más extensa desde distintas perspectivas. El segundo y el tercer aspecto están directamente relacionados con el "principio de salutarité», que trataremos en el próximo artículo, por eso ahora nos detenemos en el primero.

El fundamento de la pretensión de irreductibilidad e inviolabilidad del hombre que el creyente puede transmitir desde su logos es Dios mismo. Sólo desde él se puede sostener tal idea y resistir los envites de ideologías y prácticas que van en contra del ser humano. Las diversas concepciones antropológicas aportadas desde la sociología, la psicología, la filosofía, pueden anunciar este predicado mayúsculo del hombre, pero pueden igualmente no hacerlo. Pueden exponer argumentos, sistemas, comprensiones a su favor, pero sin un fundamento sólido que resista voces contrarias proclamadas desde sus mismos ámbitos. La teología, en cambio, sólo puede ver al hombre «aparte Dei, sub specie aeternitatatis» ${ }^{125}$. Ahí es donde se muestra que la reflexión teológica, «justamente al poner de manifiesto su antropología, de ningún modo abdica de su estatuto de teo-logía ${ }^{126}$. La teología considera al ser humano hecho a imagen de Dios, criatura querida de sus manos, como el lugar donde su Creador le visita y se manifiesta. Dios dona un estatuto a sus criaturas que las hacen insumisas a todo intento de sumisión.

\footnotetext{
125 L'homme, 43/44.

126 Ibid., 43/44. Nota 9.
} 
Por su carácter icónico y semejante al Deus ex lex, podemos decir análogamente sobre el hombre que él también está situado ex lex. Está situado fuera de toda constricción impuesta en su historicidad que trate de reducirlo o someterlo. En virtud de la transcendencia que el hombre refleja en negativo, del significado de sí mismo al que se refiere como significante, del término remitente como símbolo originario, el ser humano se muestra como inobjetivable. Similar al término enigmático veterotestamentario Yahvéh, utilizado para referirse a Dios subrayando su distancia insalvable, hay un todo inaprehensible en el hombre por la semejanza e imagen que él mismo es de su Creador. Res sacra homo homini reza el adagio latino. Algo inalcanzable, cuasi sagrado, es el hombre para sus semejantes.

Expresión de tal sacralidad es la libertad donada y definidora de nuestra identidad. A diferencia de otras concepciones, la libertad del hombre en el cristianismo no es una conquista, algo por lo que deba luchar o arrebatar a sus semejantes o a un Tercero Trascendente ${ }^{127}$. Le constituye per $s e^{128}$. Ella es la verdadera huella del Creador ${ }^{129}$. En la capacidad originaria que posibilita abrir de arriba a abajo todo límite y constricción, se muestra que el ser humano no es una mónada aislada, sino una criatura referida y relativa. Referida por Dios y relativa a Él y al resto de criaturas. Este espacio de relatividad, de toma de consciencia de una serie de realidades que le circundan, posibilita activar el ejercicio de la libertad. Desde ella debe responder. En ella, el ser humano está sujeto, paradójicamente, al ejercicio responsable de su libertad. No se puede evadir de tal situación. Aunque abdique de tal propiedad, aunque su realización vaya incluso en contra de sí mismo, toda respuesta será realización concreta y manifestación de su libertad y, como consecuencia, de su Creador.

Incluso de cara a Dios podríamos permitirnos una licencia justificados por la misma lógica del discurso de nuestro autor: Res sacra homo Dei. Cosa sagrada es el hombre para Dios, tanto por su procedencia como por su identidad. Identidad otorgada por una Alteridad Trascendente que lejos de alienar, dona un espacio de libertad, de autonomía, de responsabilidad, mayor que cualquier otra ${ }^{130}$. Identidad que Dios mismo respeta en

127 Cf. B. Bourgine. "Le style". En La margelle du puits. Adolphe Gesché, une introduction, dirigido por B. Bourgine, P. Rodrigues y P. Scolas, 156-159. Paris: Cerf, 2013.

128 Cf. Le Sens, 21/31.

129 Cf. Ibid., 29/39.

130 Cf. Ibid., 52ss./63ss. 
su diferancia. En este caso, e inspirado por Derrida, Gesché pensará la trascendencia no sólo como cualidad de Dios, sino como posibilidad para el hombre: transcendance, será el término para referirse a aquello que permite a los otros que sean diferentes ${ }^{131}$. Así, el hombre «es también y al mismo tiempo ese ser cuyo sentido no se descifra solamente con letras profanas, sino también con letras sagradas, santas y divinas» ${ }^{132}$. Desde la trascendencia de Dios, el hombre tiene una estructura, una capacidad para salir más allá de sus límites y elevar el pensamiento, la confesión y la acción como humilde ofrenda a su Creador, actualizando la huella, imago Dei, que él mismo es.

La transcendencia del hombre pro-vocada por Dios y realizable de cara a sí mismo y a cuanto le rodea, será el rasgo distintivo del ser humano como criatura. Señal de ese espacio siempre por habitar es el enigma con el que ha de aprender a vivir y del que ha de aprender para vivir. «Que el hombre sea así parcialmente un enigma para sí mismo y para los demás, esto es lo que le salva de estar totalmente absorbido y apresado por una mirada ${ }^{133}$. La transcendencia manifestada en su enigma no sólo califica al ser humano, sino que lo define en cuanto capacidad. Hermosa y paradójica imagen el ser definidos por el Transcendente como capaces de transcendencia. «"El hombre sobrepasa infinitamente al hombre", decía Pascal» ${ }^{134}$.

«Así pues, en nosotros se encuentra una dimensión oculta, que me gustaría denominar un "mapa del cielo", como el que se dice que tienen las aves migratorias que trazan por el cielo su camino. El hombre necesita un cielo; necesita "la bóveda de una larga frase por encima de la existencia" ${ }^{135}$.

En función de esta capacidad, el teólogo de Lovaina dará un paso más fundamentando en ella la propuesta que Dios hace al hombre.

Desde esa infinita bóveda el ser humano puede leerse, descifrarse, alentar la esperanza de que el Misterio resolverá el enigma que él mismo es. Así, la irreductibilidad, la inviolabilidad amplían su significado indicando que no implican una autonomía carente de relación, antes bien,

131 Cf. Ibid., 173. Note 1/188. Nota 46.

132 La Destinée, 102/104.

133 Le Sens, 27/37.

134 L'homme, 43/45.

135 La Destinée, 55/57. 
sugieren al hombre la conveniencia de tomar distancia de sí mismo para adquirir conciencia de su carácter relativo y su necesidad de relación. Esta distancia instauradora de sentido, donadora de identidad, esta relación que viene desde lo alto permite leer en él mismo la propuesta que Dios hace al ser humano al quererlo como hijo suyo ${ }^{136}$.

La filiación adoptiva de ser hijos en el Hijo, otorgada por el Espíritu Santo en el bautismo, es la manifestación suprema de la dignidad del ser humano. "Vivir la propia vida como la de un hijo de Dios es una manera de ser hombre» ${ }^{137}$. La más divina para los cristianos y la propuesta más humanizadora para quienes no lo reconocen o lo han olvidado. La filiación adoptiva desvela una remitencia original a la paternidad de Dios en cuanto identidad y a su voluntad respecto al ser humano. «El Hijo de Dios se ha hecho hombre para que el hombre se haga Dios», dirá Atanasio en De Incarnatione Verbi, 54, 3, o mejor, evitando el riesgo de la fusión y siguiendo a Ireneo, Gesché apuntará: «Esta es la razón por la que el Verbo se hizo hombre: que el hombre, al recibir la filiación adoptiva, se convierta en hijo de Dios» (Adv. hae. III, 19,1) $)^{138}$.

Esta es la clave para vivir la existencia y remitirla a un destino, para sacar al hombre de la redundancia en que puede introducirse si renuncia a lo que es y a quien así lo ha hecho. Como dijo Pascal, «miseria del hombre sin Dios. Grandeza del hombre con Dios» (Pensamientos, 60). Pero, ¿cómo mostrarlo? ¿Cómo proponerlo? ¿Es tan clara esta afirmación hoy día? ¿Hasta qué punto resulta creíble? Por difícil que resulte la empresa ante ciertas antropologías, en el trasfondo de Gesché estará la pretensión de Platón en el Timeo, 29c: «seremos muy felices si podemos presentar una exposición que no sea menos verosímil que la del otro» ${ }^{139}$.

\subsection{AD EXTRA}

Los diversos intentos que realiza Gesché para mostrar una antropología sugerente y válida, con una especificidad propia en el concurso de los saberes, se encaminan a poner un espejo ante la profundidad del hombre.

136 Cf. L'homme, 108/105; Le Christ, 196/208ss.

137 Le Christ, 202/214.

138 Ambas referencias, a Atanasio e Ireneo, en Le Christ, 209, note 1/222, nota 6.

139 La Destinée, 21/22. Omitimos las cursivas que añade el autor. 
En ella emergen cuestiones como la identidad, el sentido, la finalidad y también la inquietante dificultad para el conocimiento de sí y de cuanto lo rodea y espera.

«Lo desearíamos, sin duda, pero no somos del todo transparentes a nosotros mismos. Acaso haya que comenzar por ahí para comprenderse bien. El hombre es ese ser en perpetua búsqueda de su humanidad y del secreto que ella encubre. Cuestión que no tiene nada de académica. Es existencial: cercana a las cuestiones de nuestro destino, pues presentimos que el hecho de inclinarnos sobre el brocal de nuestro propio pozo acaso nos conduzca al sentido de nuestra vida. Que no tenga que decir un día: “¿He pasado de largo?”»"

De esta manera tan bella, Gesché plantea crudamente la gran pregunta que todo ser humano es y que, tarde o temprano, irrumpe en su existencia. Interrogante siempre incontestable por nosotros, resuelto parcialmente por el riesgo y la audacia, por la confianza en el camino cotidiano donde se interroga: ¿será esta mi dirección? ¿Me llevará a mi destino? Preguntas irrenunciables que hoy día son esquivadas y excusadas, pero no por ello eliminadas, pues nos pertenecen radicalmente, ya que somos esas mismas preguntas.

«En la realidad entera, en nosotros y en torno nuestro, hay una parte de "nocturnidad" (H. Bosco) que nos constituye y con la que — parte inextinguible- nos construimos» ${ }^{141}$. Eso es lo primero que hay que asumir. Lejos quedan la clarividencia del conocimiento y el avance implacable de la técnica, que no son capaces de vislumbrar el destino que interroga el presente de cada uno. Esta es la muestra preclara de nuestra naturaleza transcendente, que «quiere decir aquí, en el corazón de nuestra indudable inmanencia, esa dichosa indecisión que nos enseña que la verdad siempre hemos de buscarla, sin que se nos proponga nunca en términos exactos» ${ }^{142}$.

Aquí es donde la teología tiene su palabra, donde puede ir más lejos que la filosofía o la ciencia, pues ella es la única que se interesa en primer término "por aquello que advendrá al hombre, por aquello que él espera más allá de la ultima linea rerum ${ }^{143}$. En este sentido podemos decir que la teología habla, en términos seculares, de la felicidad del hombre. Con

\footnotetext{
140 L'homme, 15/17.

141 Ibid., 19/21.

142 La Destinée, 12/13-14.

143 Le Sens, 85/98.
} 
ello no abandona su objeto, pues el logos de la fe considera que tal felicidad es Dios mismo, sino que lo muestra comprensible. Quizá lo haga con una categoría gastada o sospechosa, al haberla identificado con el placer, pero no deja de ser cercana a la idea de salvación, tan específica y central de nuestra tradición.

Hablar en estos términos, quizá pueda parecer el retorno a uno de los aspectos de la crítica marxista sobre el cristianismo: «el opio del pueblo» como conjunto de promesas ilusorias que anestesian la conciencia del hombre y lo alienan mermando su capacidad de acción y transformación. Pero la consecución de la felicidad en orden a su destino, a la salvación - hablando en cristiano- tiene un correctivo intrínseco. Dios es el que trae la salvación a un mundo concreto donde, «al lado de las alegrías y felicidades de los hombres, reinan el sufrimiento y la desgracia» ${ }^{144}$. Por eso, el discurso teológico sobre el hombre no pone entre paréntesis la realidad, no hunde al ser humano en el abismo de su enigma y lo consuela desde un cielo por venir, sino que le propone una tarea en su existencia. Entre su origen y su destino, en el tiempo que habita en el cosmos, o si se prefiere, en la sociedad, el ser humano tiene el mandato de una praxis. Gesché se permitirá la expresión "practicar a Dios» ${ }^{145}$. Con ella se refiere a tres aspectos concretos de la existencia cristiana:

En primer lugar, es expresión del lenguaje autoimplicativo de la fe. Esta expresividad revela que la fe no es ideología, sino relación personal con quien la provoca. Relación que llama a unificar todas las dimensiones y etapas de la vida personal en una misma dirección desde la profundidad, lugar donde se inicia tal relación, hasta la diversidad de concreciones que la expresan. Sin duda una propuesta de sentido ante la cultura del presente, la atomización del sujeto y su fragmentación.

En segundo lugar, la concreción de «cuanto hicisteis a unos de estos hermanos míos más pequeños [...]» en Mt 25,31ss. En ella se desvela la identidad del cristiano ante los otros. Identidad mostrada en la actualización del Reino que tiene como meta y pro-voca a su realización, en la concepción teo-lógica del hombre como lugar donde Jesucristo sale a su encuentro. En palabras de Balthasar: «Así practica un cristiano: pone en circulación los dones recibidos a favor de los semejantes, $[\ldots]$ como

144 Ibid., 141/156.

145 La Destinée, 175/176. 
acto de concentración retrospectiva — haced esto en memoria mía-pero siempre con miras a la expansión del mundo» ${ }^{146}$.

Por último, la vía práctica de Pascal presentada en los Pensamientos, 233 , con el famoso «argumento de la apuesta». Ante la incomprensibilidad última del Misterio y la inevitable suspensión de juicio ante el infinito, también podemos resolvernos en el terreno de la acción. Arriesgarse a dar el salto de la praxis es la opción más razonable cuando parecen agotados otros caminos en la búsqueda del Deus absconditus.

En función de esta praxis, según la propuesta de Gesché, el cristiano atisba y anticipa su destino. La relación, el conocimiento de Dios, no puede separarse de la relación con los hombres ${ }^{147}$. De igual manera, en función de esta relación, quienes no conocen a Dios podrán hacerse una primera idea, semejante e icónica de Él. El creyente es por esto sujeto de responsabilidad, pues su imagen de Dios - teo-logía- y su «práctica de Él» - teo-praxia-, mostrarán, ad extra, la plausibilidad de ser hombres según Dios quiere y revelará la credibilidad y validez de la antropología teologal que propone nuestro autor ${ }^{148}$.

Sobre el valor de la praxis se cierne de ordinario la sombra de cierto pelagianismo, de una reducción de las capacidades de Dios y de una pueril supervaloración de las capacidades del hombre, pensando que de él depende en gran medida la consecución de su felicidad, incluso que de él depende el conocimiento y la revelación de Dios. Sobre este aspecto Gesché reflexiona de manera equilibrada a partir de la fórmula Etsi deus non daretur ${ }^{149}$, siendo consciente de los límites que desarrollos similares, como la teología de la liberación, han tenido al respecto. No en vano dedica casi veinte páginas a sugerir correcciones a dicha teología ${ }^{150}$. De igual manera, señala cierto pro-ateísmo detrás de esta fórmula ${ }^{151}$. En ese equilibrio, autolimitado y corregido desde dentro, es donde nuestro autor se sitúa. «Sería dramático que perdiéramos el sentido de la eternidad. Pero también sería dramático que perdiéramos el de la temporalidad» ${ }^{152}$.

146 H. U. von Balthasar. Quién es cristiano. Salamanca: Sígueme, 2000, 99, 104.

147 Cf. La Destinée, 178-179/180.

148 Cf. P. Rodrigues. Pensar al hombre. Antropología teológica de Adolphe Gesché. Salamanca: Universidad Pontificia de Salamanca, 2012.

149 Cf. Le Cosmos, 111-117/239-245; Id. La paradoja del cristianismo. 17-52.

150 Cf. Le mal, 142-160/144-161.

151 Cf. Le Cosmos, 114/242.

152 La Destinée, 182/183. 


\subsection{El HOMBRE, INVERSIÓN REVELADORA}

Gesché ha tratado de contemplar el hombre desde arriba y ha descubierto en su fondo enmarañado un espejo vuelto hacia el cielo. En el ser humano examinado en su insondable profundidad, ha encontrado la huella indeleble de su capacidad innata de transcendencia per natura Dei. Por ella, no sólo nuestra disciplina es estrictamente teo-logía, aun hablando del hombre, sino que el hombre mismo es teología. Palabra sobre Dios desde su origen hasta su destino, el ser humano se encuentra en su vida tratando de identificar los signos de interrogación en los que se contiene su existencia. Signos que indican la pertenencia a su Creador.

Paradójicamente, los dos límites impuestos en la inauguración y clausura del ser humano son límites abiertos, pues son preguntas que apuntan a un más allá:

«¿No será exactamente ahí donde nos hallamos nosotros, a quienes se nos ha delegado como portadores de signos? Pienso en la mayéutica de Sócrates, que nos servirá de modelo. Dar a luz, transmitir respuestas que uno va a interrogar y a escrutar como enigmas afortunados que hay que descifrar para encontrar en ellos el secreto de su ser» ${ }^{153}$.

En este camino todo puede y debe ser cuestionado, no sólo las respuestas, sino las preguntas. En nuestro caso, el hombre es pregunta, manifestando así su responsabilidad, su tarea, su libertad y la relación con sus semejantes como el lugar, no único y quizá tampoco el específico, en el que encontrarse con otras preguntas y respuestas que alienten su búsqueda.

Estas preguntas y respuestas que el mismo hombre es, son la inversión reveladora de Dios, el signo de su transcendencia en nuestra inmanencia que grita y sufre dolores de parto hasta ver a su Hijo conformado en el hombre (cf. Gal 4,19). En este ordo filiationis «nos encontramos con algo verdaderamente fascinante: la posibilidad de descubrir que es en Dios donde nosotros conocemos lo que somos y que es en nosotros donde aprendemos lo que él es» ${ }^{154}$.

En el seguimiento y configuración con Jesucristo, es donde se desvela la identidad verdadera del hombre y donde se explicita la del cristiano;

153 L'homme, 26/28.

154 Le Christ, 222/236. 
en ella manifiesta que «ha apostado toda su existencia a una posibilidad que nos brindó Jesucristo, el Hijo de Dios, obediente por todos nosotros hasta la cruz: participar en el sí a Dios, un sí obediente que redime al mundo» ${ }^{155}$. Este sí es lo único que se pide. Un sí que pone de manifiesto el papel protagonista del ser humano en el acto salvador de la creación: «Dios que te ha creado sin ti, no te salvará sin ti» ${ }^{156}$, máxima de san Agustín recordada por nuestro autor, que indica la actividad segunda de la pasividad primera. Lo recibido debe poder expresarse como tal, mostrando que es una prenda de la plenitud por recibir. A los hombres «se nos pide "simplemente" creer en ello» ${ }^{157}$.

La filiación, así, resulta una propuesta redundantemente positiva en favor de Dios, del hombre y de sus semejantes. En estos últimos se expresa como fraternidad. En ellos, el cristiano no actúa como en un laboratorio a la espera de su verificación escatológica, sino que facilita el kairós de Dios en el mundo presente, abre vías de eternidad en el espesor del tiempo e instaura momentos de densidad ontológica en la relación ética. Por su identidad, por su felicidad, por su destino, el hombre tiene prohibido tratar a cualquier ser humano de manera distinta a un hijo de Dios, llamado a la filiación divina y a la resurrección; tiene prohibido considerarlo como sometido a sus poderes y tomar unas decisiones que pudieran ir en contra de su destino trascendente, sobre el cual no tiene ningún poder. En este respeto cuasi sagrado, en esta donación de la propia vida donada hasta la cruz, es donde se manifiesta el exceso de la antropología teologal que propone la fe. En ella, el origen, el camino y el destino del hombre son un todo unificado, abierto e infinito, tejido por bellos momentos de amor y entrega divina a los semejantes.

«En el cristianismo, la gloria implica la Cruz, y el destino teologal (que es lo que afecta al hombre) implica que se tome en cuenta la dimensión ética. La afirmación de que "era necesario que Cristo muriera para entrar en la gloria" (Lc 24,26) indica que, salvo traición de tipo moral y espiritual, nadie ¡ni el mismo Dios! puede evitar el hecho de la condición humana; y que nadie podrá buscar una espiritualidad desencarnada para aproximarse a Dios» ${ }^{158}$.

155 H. U. von Balthasar. Quién es cristiano. 62. Cf. L'homme, 108/106; Le Christ, 196ss./208ss.

156 L'homme, 83/81; Le Sens, 75/87; Dieu, 157/142.

157 L'homme, 114/111.

158 Le Sens, 113/127. 
Así, la propuesta cristiana como antropología se muestra como una síntesis satisfactoria capaz de integrar armónicamente transcendencia e inmanencia, destino y sentido. No hay pues un cortocircuito entre la contingencia del hombre, su sed y el alumbramiento de una nueva creación. El ser humano se revela, a los ojos de la fe, no como un Sein zum Tode (Heidegger), sino como Sein zum Leben, für die Leben von Gott. Todo está indisolublemente unido y sellado en aquel que nos ha amado primero (cf. 1Jn 4,19) y por el que el ser humano debe lanzarse a amar, como signo y realización humanada del exceso de amor del Creador. Siendo prójimos de los hombres nos aproximamos a Dios manifestando y acogiendo su presencia. ¿Qué mayor bien? ¿Qué mejor propuesta? ¿Qué mejor noticia? ¿Qué mejor manera de verificar el principio de capacidad salvífica de la teología? Sobre este aspecto, el segundo principio epistemológico en la teología de nuestro autor, versará nuestro próximo estudio que pronto verá la luz.

\section{REFERENCIAS}

Balthasar, Hans Urs von. Gloria. Una estética teológica. Vol. 1, La percepción de la forma. Madrid: Encuentro, 1985.

Balthasar, Hans Urs von. Quién es cristiano. Salamanca: Sígueme, 2000.

Barcellos, José Carlos. O drama da salvação. Espaço Autobiográfico e Experiência Cristã em Julien Green. Juiz de Fora: Ediçoes Subiaco, 2008.

Bourgine, Benoît, Paulo Rodrigues \& Paul Scolas, dirs. La margelle du puits. Adolphe Gesché, une introduction. Paris: Cerf, 2013.

Clemente de Alejandría. Stromata. V (FP 15). Madrid: Ciudad Nueva, 2003. Clemente de Alejandría. Stromata. VII (FP 17). Madrid: Ciudad Nueva, 2005.

Cura, Santiago del. "El sufrimiento de Dios en el trasfondo de la pregunta por el mal. Planteamientos teológicos actuales". RET 2/3 (1991): 331-373.

Espezel, Alberto. "Lidentité narrative de Jésus". Revue Catholique Internationale Communio, 30, 1 (2005): 89-97.

García Mourelo, Santiago. "La monstratio theologica de Adolphe Gesché. Inspiración teológico-fundamental de su obra”. Estudios Eclesiásticos 92 (2017): 3-32. 
Gesché, Adolphe. Fichier d'Adolphe Gesché, 1928-2003. Disponible bajo acreditación en: https://bib.uclouvain.be/gesche/fr

Gesché, Adolphe. La christologie du 'Commentaire sur les Psaumes' découvert à Toura. Gembloux: Duculot, 1962.

Gesché, Adolphe. "Teología dogmática”. En Iniciación a la práctica de la teología. Vol. 1, Introducción, editado por Bernard Lauret y François Refoulé, 270-292. Madrid: Cristiandad, 1984 (1982).

Gesché, Adolphe. Le mal. Dieu pour penser I. Paris: Cerf, 1993 (trad. esp. El mal-El hombre. Salamanca: Sígueme, 1995).

Gesché, Adolphe. L'homme. Dieu pour penser II. Paris: Cerf, 1993 (trad. esp. Esp. El hombre. Salamanca: Sígueme, 2002).

Gesché, Adolphe. Dieu. Dieu pour penser III. Paris: Cerf, 1994 (trad. esp. Dios-El Cosmos. Salamanca: Sígueme, 1997).

Gesché, Adolphe. Le Cosmos. Dieu pour penser IV. Paris: Cerf, 1994 (trad. esp. Dios-El Cosmos. Salamanca: Sígueme, 1997).

Gesché, Adolphe. La Destinée. Dieu pour penser V. Paris: Cerf, 1995 (trad. esp. El destino. Salamanca: Sígueme, 2001).

Gesché, Adolphe. Le Christ. Dieu pour penser VI. Paris: Cerf, 2001 (trad. esp. Jesucristo. Salamanca: Sígueme, 2002).

Gesché, Adolphe. Le Sens. Dieu pour penser VII. Paris: Cerf, 2003 (trad. esp. El sentido. Salamanca: Sígueme, 2004).

Gesché, Adolphe. Pensées pour penser I. Le mal et la lumiere. Paris: Cerf, 2003.

Gesché, Adolphe. Pensées pour penser II. Les mots et les libres. Paris: Cerf, 2004.

Gesché, Adolphe. La paradoja del cristianismo. Salamanca: Sígueme, 2011. Gesché, Adolphe. La paradoja de la fe. Salamanca: Sígueme, 2013.

Gesché, Adolphe. La Teología. Salamanca: Sígueme, 2017.

Gil i Ribas. "La Summa Theologicae'de Adolphe Gesché”. RCatT 23 (1998): 225-230.

Gregorio de Nisa. Sobre la vida de Moisés (BPa 23). Madrid: Ciudad Nueva, 1994.

Grillmeier, Alois. Cristo en la tradición cristiana. Salamanca: Sígueme, 1997.

Ladaria, Luis F. El Dios vivo y verdadero. El misterio de la Trinidad. Salamanca: Secretariado Trinitario, 1998.

Lévinas, Emmanuel. Humanismo del otro hombre. México: Siglo XXI, 1974.

Lévinas, Emmanuel. Totalidad e infinito. Ensayo sobre la exterioridad. Salamanca: Sígueme, 1987. 
Lévinas, Emmanuel. “¿Un Dios hombre?”. En Entre nosotros: ensayos para pensar en otro, 69-78. Valencia: Pre-Textos, 1993.

Lévinas, Emmanuel. De otro modo que ser, o más allá de la esencia. Salamanca: Sígueme, 1999.

Lévinas, Emmanuel. La realidad y su sombra. Libertad y mandato, Trascendencia y altura. Madrid: Trotta, 2001.

Pascal, Blaise. Pensamientos. ed. Brunschwick. Madrid: Alianza, 2004.

Rahner, Karl. "Para la teología de la encarnación”. En Escritos de Teología IV. 4. ${ }^{\text {a }}$ ed., 131-148. Madrid: Cristiandad, 2002.

Rodrigues, Paulo. Pensar al hombre. Antropología teológica de Adolphe Gesché. Salamanca: Universidad Pontificia de Salamanca, 2012.

Villar, Alicia y Blaise Pascal. Conversación con el Sr. de Saci. Salamanca: Sígueme, 2006. 